\title{
Nerve Regeneration Restores Supraspinal Control of Bladder Function after Complete Spinal Cord Injury
}

\author{
Yu-Shang Lee, ${ }^{1,3}$ Ching-Yi Lin, ${ }^{1,3}$ Hai-Hong Jiang, ${ }^{2,4}$ Marc DePaul, ${ }^{5}$ Vernon W. Lin, ${ }^{3}$ and Jerry Silver ${ }^{5}$ \\ Departments of ${ }^{1}$ Neurosciences, ${ }^{2}$ Biomedical Engineering, and ${ }^{3}$ Physical Medicine and Rehabilitation and ${ }^{4} \mathrm{Glickman}$ Urological and Kidney Institute, \\ Cleveland Clinic, Cleveland, Ohio 44195, and 5Department of Neurosciences, Case Western Reserve University, Cleveland, Ohio 44106
}

\begin{abstract}
A life-threatening disability after complete spinal cord injury is urinary dysfunction, which is attributable to lack of regeneration of supraspinal pathways that control the bladder. Although numerous strategies have been proposed that can promote the regrowth of severed axons in the adult CNS, at present, the approaches by which this can be accomplished after complete cord transection are quite limited. In the present study, we modified a classic peripheral nerve grafting technique with the use of chondroitinase to facilitate the regeneration of axons across and beyond an extensive thoracic spinal cord transection lesion in adult rats. The novel combination treatment allows for remarkably lengthy regeneration of certain subtypes of brainstem and propriospinal axons across the injury site and is followed by markedly improved urinary function. Our studies provide evidence that an enhanced nerve grafting strategy represents a potential regenerative treatment after severe spinal cord injury.
\end{abstract}

\section{Introduction}

Classic studies have repeatedly demonstrated (Ramon y Cajal, 1928; Aguayo et al., 1981) that a favorable environment for CNS axon regrowth can be created by engraftment of a segment of peripheral nerve, which can be further augmented via the addition of growth factors (Cheng et al., 1996; Lee et al., 2002b; Tsai et al., 2005). However, the lack of significant exodus of axons from the graft had derailed the use of the peripheral nerve bridging strategy since it was first implemented by Tello in Ramon y Cajal's laboratory nearly a century ago (Ramon y Cajal, 1928). Importantly, recent papers have shown that a buildup of inhibitory reactive glial-derived chondroitin sulfate proteoglycans (CSPGs) at the peripheral nervous system (PNS)/CNS interfaces is a major impediment that curtails regenerating axons from entering but especially exiting the bridge (Houle et al., 2006; Yang et al., 2006; Busch and Silver, 2007; Alilain et al., 2011). In high cervical hemisection models of spinal cord injury (SCI), treatment at the doorways of the graft with chondroitinase $\mathrm{ABC}(\mathrm{ChABC})$, which cleaves the inhibition mediating sugar chains of CSPGs (Shen et al., 2009), can lead to regeneration of a portion of the descending

Received March 6, 2012; revised March 28, 2013; accepted April 18, 2013.

Author contributions:Y.-S.L., V.W.L., and J.S. designed research;Y.-S.L., C.-Y.L., H.-H.J., M.D., and J.S. performed research; Y.-S.L. contributed unpublished reagents/analytic tools; Y.-S.L., C.-Y.L., and J.S. analyzed data; Y.-S.L. and J.S. wrote the paper.

This project was funded by the Cleveland Clinic Foundation and National Institute of Neurological Disorders and Stroke Grants NS069765 (Y.-S.L.) and NS25713 (J.S.). We thank Brian Balog for taking care of the animals after surgery and Kevin Li assisting with animal care and data analysis. We thank Dr. Margot Damaser for providing knowledge of the evaluation of bladder pathology and sharing equipment for the bladder functional assessments.

Correspondence should be addressed to either of the following: Dr. Yu-Shang Lee, Departments of Neurosciences and Physical Medicine and Rehabilitation, Cleveland Clinic, 9500 Euclid Avenue, NE63, Cleveland, OH 44195, E-mail: leey2@ccf.org; or Dr. Jerry Silver, Department of Neurosciences, School of Medicine, E653, Case Western Reserve University, 10900 Euclid Avenue, Cleveland, 0H 44106, E-mail: jxs10@case.edu.

DOI:10.1523/JNEUROSCI.1116-12.2013

Copyright $\odot 2013$ the authors $\quad 0270-6474 / 13 / 3310591-16 \$ 15.00 / 0$ innervation to the cervical cord, lying just beyond the lesion, followed by restoration of a good measure of forepaw mobility (Houle et al., 2006) or diaphragm function (Alilain et al., 2011). Having bypassed the lesion, but being directed into gray matter, regenerating axons tended to remain within their segment of exit from the graft, so it was unknown whether critical functions associated with the far caudal spinal cord, such as bladder control, could also be impacted by this approach. Also, it was unknown whether a similar strategy could be used in a more clinically challenging complete transection injury.

Proper urine storage and micturition in normal animals and humans is complex, requiring the spinal cord to integrate information arising from the brain, bladder, and urethra (de Groat et al., 1998; Fowler et al., 2008; Cruz and Cruz, 2011). SCI results in the loss of supraspinal control of the lower urinary tract and an inability to coordinate activity between urinary bladder smooth muscle and external urethral sphincter (EUS) striated muscle, resulting in a severe condition known as detrusor-sphincter dyssynergia (DSD) (Kruse et al., 1993; Fraser, 2011). Although much work in bladder recovery after SCI has focused on pharmacological intervention and/or functional electrical stimulation of the bladder or peripheral nerves (Kontani and Hayashi, 1997; Cameron, 2010), relatively few studies have focused on central neuronal regeneration for the recovery of efficient micturition (Cruz and Cruz, 2011). Here we used adult rats with complete thoracic cord transections that have been bridged by a combination of multiple peripheral nerve autografts (PNGs) covered by an acidic fibroblast growth factor (aFGF)-laden fibrin matrix plus ChABC delivered to the graft and at the graft/host interfaces. We provide physiological, anatomical, and pharmacological evidence of a surprising degree of regeneration from particular brainstem centers past the distal graft/cord interface, with some axons reaching all the way to lumbo-sacral levels and with return of bladder control. 


\section{Materials and Methods}

Animal groups. One hundred twelve adult female Sprague Dawley rats (225-250 g; Harlan) were assigned randomly and equally into seven groups (16 rats per group): (1) sham group (laminectomy only); (2) Tx-only group (T8 spinal cord transection only); (3) PNG group (T8 transection with PNG treatment); (4) aFGF + ChABC group (T8 transection with aFGF + ChABC treatment); (5) PNG + ChABC group (T8 transection with PNG + ChABC treatment); (6) $\mathrm{PNG}+$ aFGF group (T8 transection with PNG $+\mathrm{aFGF}$ treatment); and (7) PNG $+\mathrm{aFGF}+$ ChABC group (T8 transection with PNG + $\mathrm{aFGF}+\mathrm{ChABC}$ treatment). One rat in each of the sham, aFGF + ChABC, $\mathrm{PNG}+\mathrm{ChABC}$, and $\mathrm{PNG}+\mathrm{aFGF}+\mathrm{ChABC}$ groups died prematurely. Two rats from each of the Tx-only, PNG, and PNG + aFGF groups also died prematurely. Therefore, a total of 102 rats completed the entire sequence of tests. All animal procedures followed National Institutes of Health guidelines and were approved by the Institutional Animal Care and Use Committee of the Cleveland Clinic. Animals were housed in ventilated, humidity-controlled $(50 \%)$, and temperature-controlled $\left(23-25^{\circ} \mathrm{C}\right)$ rooms on a $12 \mathrm{~h} \mathrm{light/dark} \mathrm{cycle.}$

Spinal cord surgery, multiple peripheral nerve segment transplantation, and ChABC injection. All surgical procedures were conducted under aseptic conditions. Before surgery, all animals were anesthetized by $2 \%$ isoflurane mixed with oxygen. The animals were maintained on a heating pad, and the rectal temperature was monitored and maintained within $\pm 1.5^{\circ} \mathrm{C}$ of normal temperature during surgery. Bipolar electrocauterization was used to minimize bleeding. Rats in the sham group underwent a partial laminectomy only at the T8 level. Rats in the Tx-only group underwent a similar partial laminectomy, followed by two complete transverse cuts of the spinal cord at the T8 level, creating a gap of $\sim 5 \mathrm{~mm}$. A surgical microscope was used to ensure the complete removal of neural tissue from the $5 \mathrm{~mm}$ gap (nothing was inserted in this gap). Rats in the PNG group underwent a spinal cord transection as described above, and then the $5 \mathrm{~mm}$ gap was bridged using PNG auto-transplantation $(\sim 18$ intercostal nerve segments) as described previously (Lee et al., 2002b). The nerve segments were slightly inserted into both rostral and caudal stumps (up to $0.5 \mathrm{~mm}$ ) to bridge the gap. A critical next step in this procedure is the fixation of the vertebral column in a dorsiflexed position using a compressive S-shaped monofilament surgical steel wire (B\&S 20 gauge, DS20; Ethicon) loop. The loop is composed of two hooks and a central handle for twisting. After hooking at the bases of the T7 and T10 spinal processes, the loop is secured to the vertebral column with two sets of non-absorbable threads (Cheng and Olson, 1995). The thread is passed underneath the rib and then tightened with the loop. The central handle is twisted to provide stabilization. The continuing presence of the monofilament was confirmed by postmortem analysis. Rats in the ChABC + aFGF group also underwent T8 spinal cord transection, but then $3 \mu \mathrm{l}$ ( $1.5 \mu \mathrm{l}$ at each cord stump adjacent to the lesion) of ChABC ( $1 \mathrm{U} / \mathrm{ml}$; Seikagaku America) was injected into the spinal cord through glass pipettes via a Hamilton syringe. After the injections, a mixture of

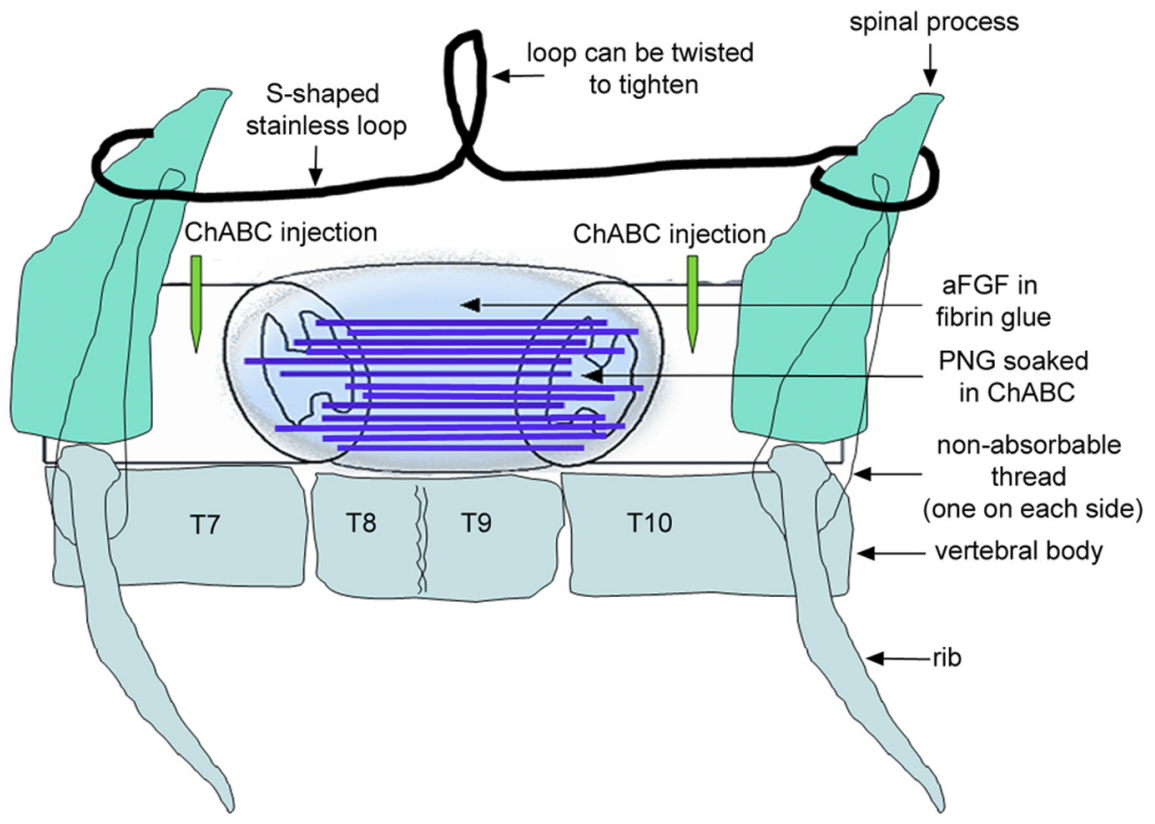

Figure 1. A schematic diagram illustrates the placement of the PNG (collected from intercostal nerves and soaked in ChABC before the transplantation), aFGF in fibrin glue, microinjection of ChABC into the spinal cord, and spinal column stabilization in PNG + aFGF + ChABC-treated animals. Vertebrae T8 and T9 have been juxtaposed to save space.
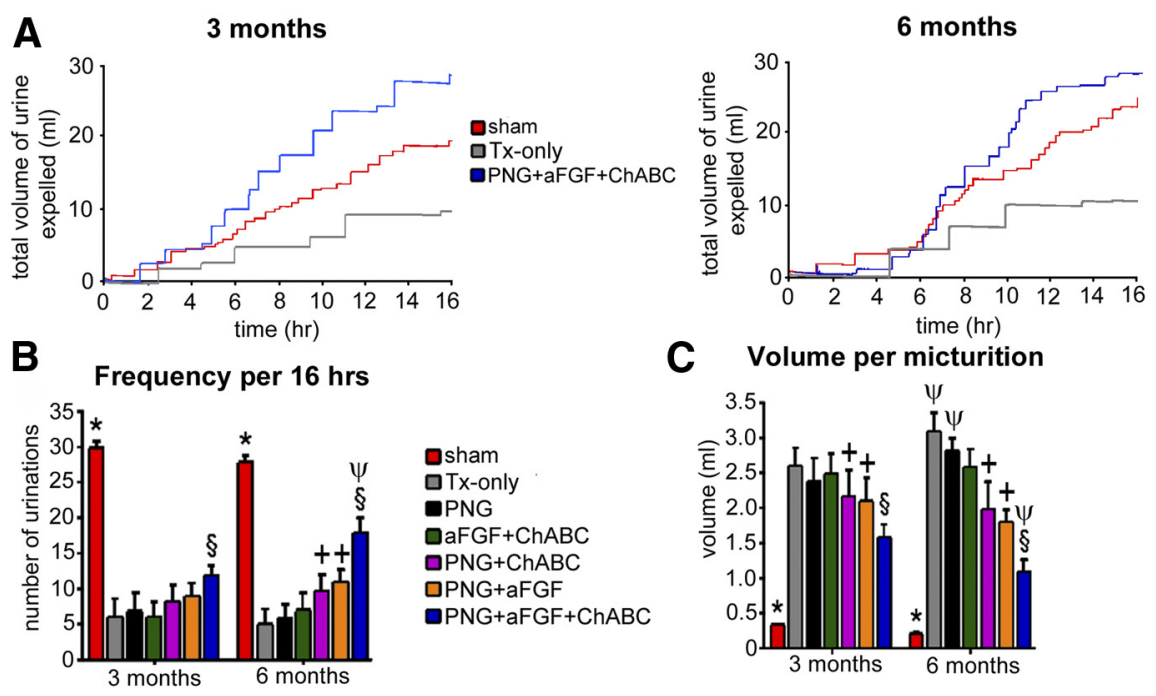

Figure 2. $\quad$ PNG + aFGF + ChABC improves micturition patterns after complete $S C l$. Representative metabolic cage voiding patterns were from select groups $(\boldsymbol{A})$ and quantification of the results $(\boldsymbol{B}, \boldsymbol{C})$ from each group at 3 and 6 months after $S C$. In each step-like curve of the graph, the horizontal line represents individual micturition events, and the vertical lines are the volume of urine expelled (change from baseline). PNG $+\mathrm{aFGF}+\mathrm{ChABC}$ animals showed higher frequencies and lower volumes per micturition than the other $\mathrm{SCl}$ groups. There results were significant when compared with all SCl groups $\left({ }^{*} p<0.05\right)$, when compared with Tx-only, PNG, and aFGF + ChABC groups ( $\left.{ }^{\dagger} p<0.05\right)$, when compared with the Tx-only, PNG, aFGF + ChABC, PNG + ChABC, and PNG + aFGF group $\left({ }^{\S} p<0.05\right)$, and when compared with 3 months with its own group ( $\left.{ }^{*} p<0.05\right)$.

aFGF ( $1 \mu \mathrm{g}$; R\&D Systems) and fibrin glue was applied to fill the $5 \mathrm{~mm}$ gap. Rats in the PNG + ChABC group received spinal cord transections, which were followed by PNG auto-transplantation with $3 \mu \mathrm{l}(1.5 \mu \mathrm{l}$ at each cord stump adjacent to the lesion) of ChABC injected into the spinal cord. Rats in the PNG + aFGF group received spinal cord transections, which were followed by PNG auto-transplantation with only the aFGF/ fibrin mixture application on top of the grafts and fixation of the vertebral column that was described above. Rats in the PNG + aFGF + ChABC group received spinal cord transection and all the treatments in full combination as described above (for a schematic diagram of this entire intervention, see Fig. 1). In all experiments in which ChABC was 
A
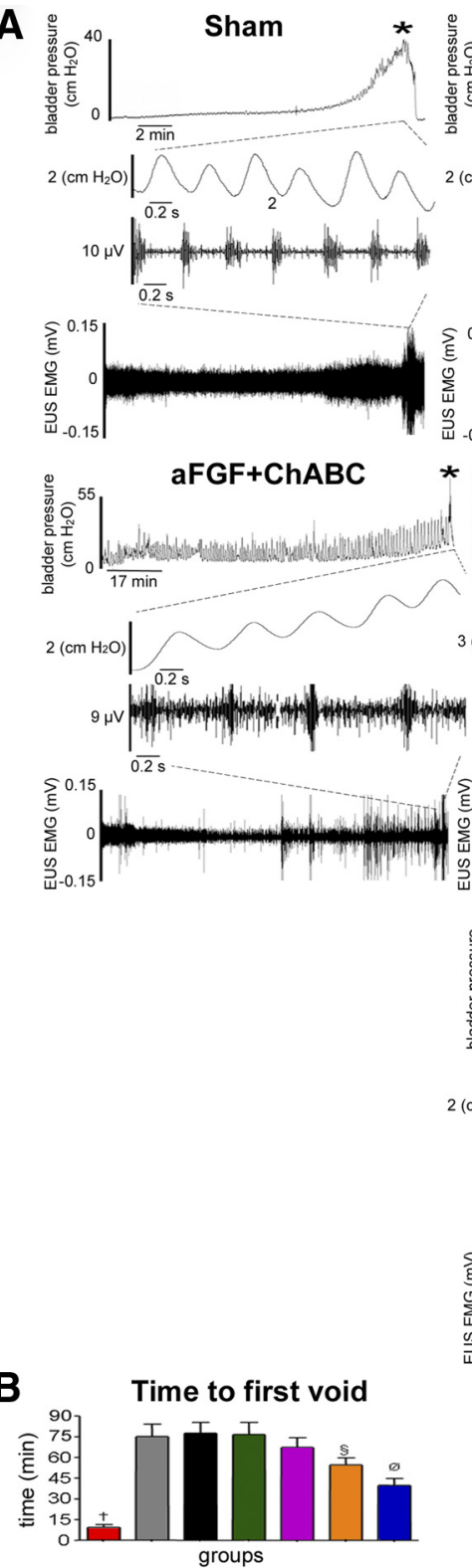

Voiding efficiency

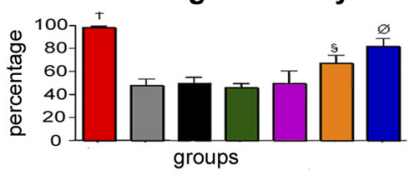

C Number of animals with EUS bursting during voiding
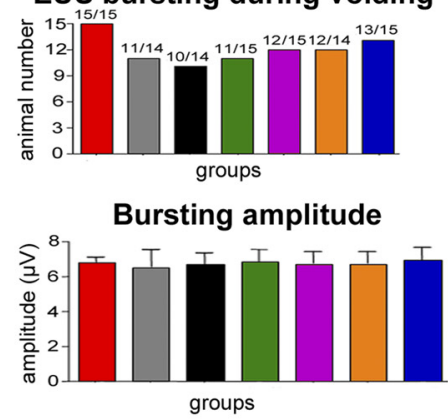

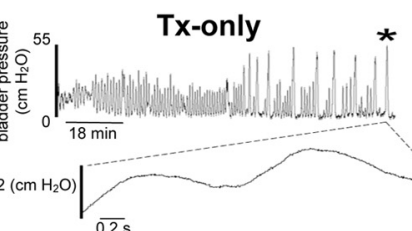

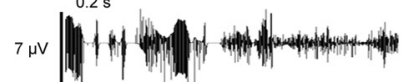
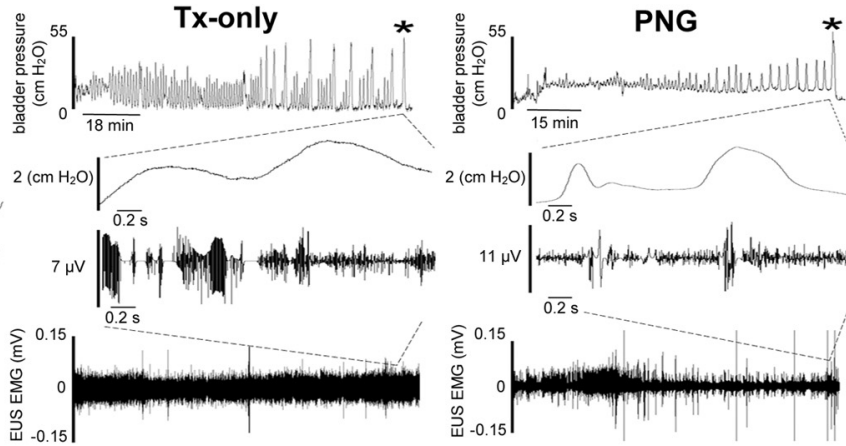

$\left.2\left(\mathrm{~cm} \mathrm{H}_{2} \mathrm{O}\right)\right|_{0.2 \mathrm{~s}}$
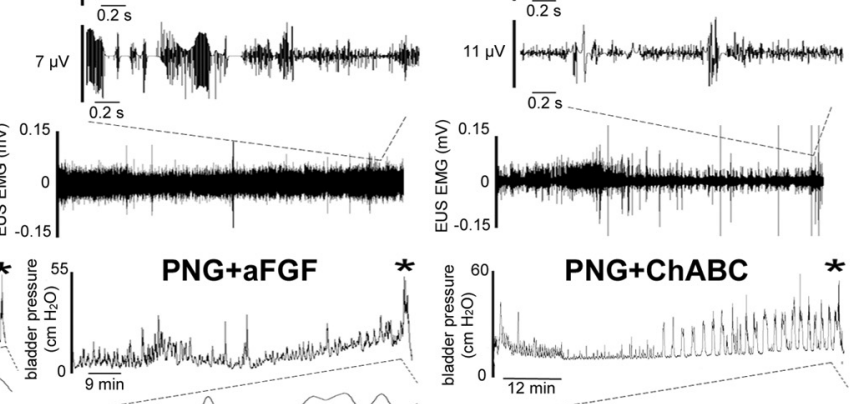

$3\left(\mathrm{~cm} \mathrm{H}_{2} \mathrm{O}\right)$
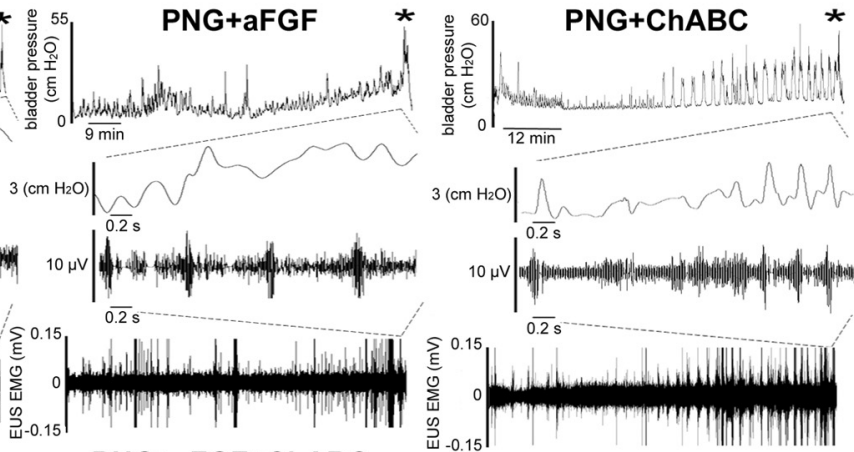

PNG+aFGF+ChABC
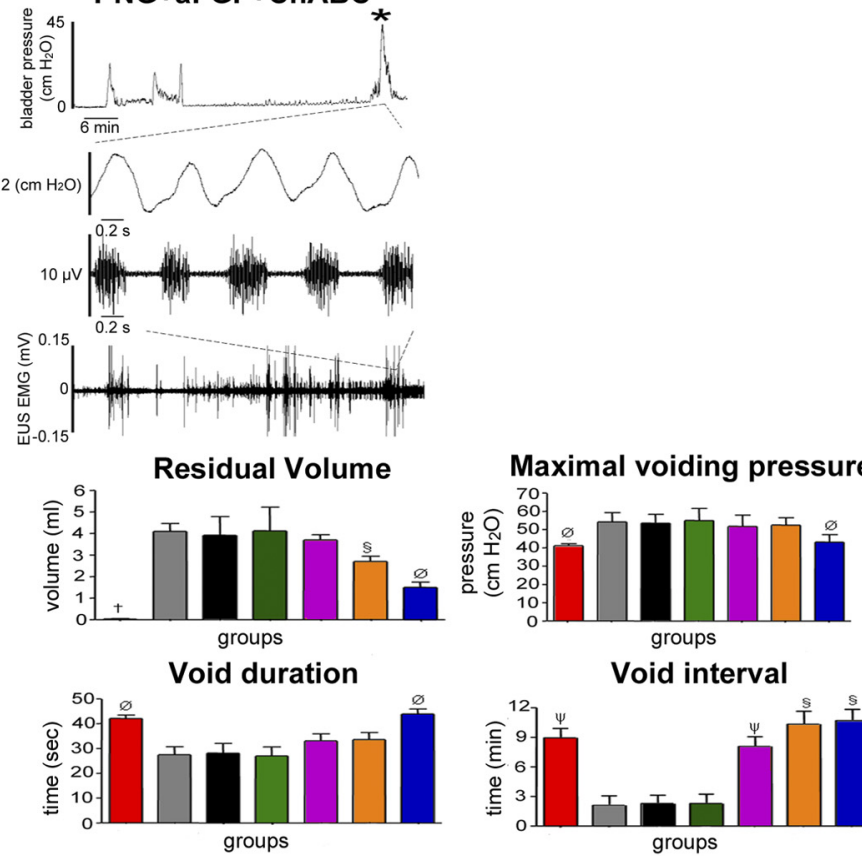

Void interval
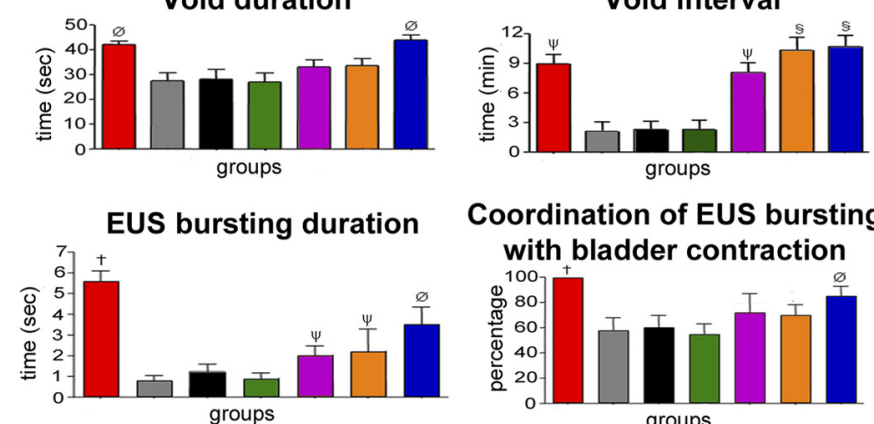

Coordination of EUS bursting with bladder contraction
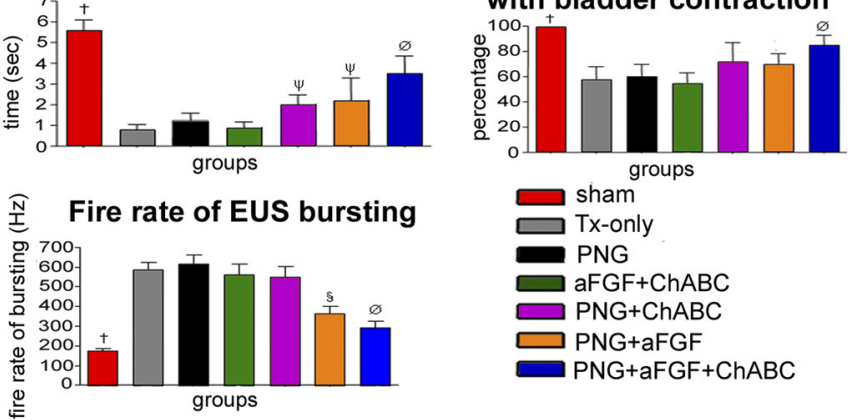

Figure 3. $\mathrm{PNG}+\mathrm{aFGF}+\mathrm{ChABC}$ improves urodynamics and bladder/EUS coordination after complete SCl. $\boldsymbol{A}$, Representative voiding and bladder pressure recordings (top 2 panels; ${ }^{*}$ indicates micturition point) and EUS EMG activity (bottom 2 panels) were recorded for each group at 6 months after $S C$. The two middle panels show magnified portions at the (Figure legend continues.) 
used, the nerve segments were collected and soaked in ChABC solution $(10 \mu \mathrm{l}$ of ChABC in $1 \mathrm{ml}$ of saline) for $\sim 1 \mathrm{~h}$ before implantation (Neubauer et al., 2007). The bladders of all spinal-cord-transected rats were expressed manually at least twice per day throughout the experimental period.

The measurement of micturition patterns using metabolic cages. At 3 and 6 months after spinal cord surgery, animals were placed in a metabolic cage (Braintree Scientific) for the measurement of voiding patterns. The voided urine was collected by a computerized system to record micturition volume and frequency. Animals were kept in this cage for $16 \mathrm{~h}$ with ample water and food during the period of urine collection and measurement. Each animal was recorded at least three times (with $3 \mathrm{~d}$ separating each recording session), and then this data were averaged to represent the voluntary micturition pattern of an individual animal. The criteria for the micturition pattern analysis included the frequency of voiding per $16 \mathrm{~h}$ and the volume per voids. The total volume of expelled urine was not included because of variation of water intake between the individual animals.

Urodynamics/cystometrogram and electromyography recordings. After the metabolic cage studies, rats at 6 months after surgery were anesthetized with $2 \%$ isoflurane, and a catheter was inserted through the urethra into the bladder for the subsequent delivery of saline. Fine-wire electrodes also were inserted percutaneously on both sides of urethra for subsequent measurements of EUS electromyography (EMG) activity. We used 50 - $\mu \mathrm{m}$-diameter Teflon-insulated platinum wire ( $2 \mathrm{~mm}$ exposed tip; A-M Systems) that was inserted into the urethra via the vagina bilaterally along the mid-urethra using a 30 gauge needle. The urethra can be easily identified where it bulges in the anterior vaginal wall. Next, the rats were placed in a restraining apparatus and al-

lowed to recover from isoflurane anesthesia for $1 \mathrm{~h}$ before the following evaluations were performed. Continuous cystometrograms (CMGs) were collected using constant infusion $(0.08 \mathrm{ml} / \mathrm{min})$ of saline (SP 100i singlesyringe infusion pump; World Precision Instruments) through the catheter into the bladder to elicit repetitive voids, which allowed collection of data for a large number of voiding cycles. The electrodes were connected to an alternating current amplifier (model P511; Astro-Med) with high- and low-pass frequency filters at $10 \mathrm{~Hz}$ and $1 \mathrm{kHz}$ and a recording system (Dash 8X; Astro-Med) at a sample frequency of $10 \mathrm{kHz}$.

Spinal cord re-transection and pharmacological studies. At 6 months after spinal cord surgery and/or treatment, the T5 level of the spinal cord

$\leftarrow$

(Figure legend continued.) point at which micturition occurred. Animals that received PNG + $\mathrm{aFGF}+\mathrm{ChABC}$ treatment had much reduced amplitudes and frequencies of non-voiding bladder contractions and much better coordination between EUS EMG bursting activity and bladder contractions during the micturition point. Quantification of the $C M G$ results $(\boldsymbol{B})$ and EUS EMG bursting patterns $(\boldsymbol{C})$ during voiding shows that the triple-combination animals had the longest durations of EUS EMG bursting activity, better coordination between bladder contractions and EUS bursting activity during voiding, and the lowest firing rates of bursting when compared with animals that received alternative treatments. There results were significant when compared with all SCI groups $\left({ }^{\dagger} p<0.05\right)$, when compared with Tx-only, PNG, and aFGF + ChABC groups ( $\left.\psi_{p}<0.05\right)$, when compared with Tx-only, PNG, aFGF + ChABC, and PNG + ChABC groups ( $\left.{ }^{\S} p<0.05\right)$, and when compared with the Tx-only, PNG, aFGF + ChABC, PNG + ChABC, and PNG + aFGF group $\left({ }^{6} p<0.05\right)$. was exposed and then completely transected by two cuts. A pledget of Gelfoam soaked with $4 \mu \mathrm{l}$ of $10 \%$ fluorescent conjugated biotinylated dextran amine (BDA) (Sigma) also was placed in the T5 spinal cord lesion site for the anterograde tracing study (see below). At 2 weeks after spinal cord re-transection, the animals were used to retest bladder function again using metabolic cages as well as analyses of urodynamics and EUS EMG recordings. In addition, animals in each SCI group were given either a serotonin $(5-\mathrm{HT})$ receptor antagonist $(5 \mathrm{mg} / \mathrm{kg}$ methysergide, i.p., once per day for $3 \mathrm{~d}$ ) or $\alpha$-methyl-DL-tyrosine [which depletes tyrosine hydroxylase (TH) at nerve terminals; $250 \mathrm{mg} / \mathrm{kg}$, i.p., once per day for $3 \mathrm{~d}$ ], and then bladder function was tested again at the end of the third day of drug treatment.

Bladder morphology studies. Animals were perfused transcardially with $4 \%$ neutral paraformaldehyde (PFA) in $0.01 \mathrm{~m} \mathrm{PBS,} \mathrm{pH} \mathrm{7.4.} \mathrm{The} \mathrm{bladders}$ of all animals were collected, and weight wet was recorded. The bladders were further fixed with $4 \%$ PFA for $1 \mathrm{~d}$. The bladders were then transferred to $30 \%$ sucrose, cryostat sectioned transversely $(8 \mu \mathrm{m})$ at the level of mid-bladder, and stained with Masson's trichrome for additional morphological analysis under the light microscope.

Immunostaining of nerve fibers in the spinal cord. After transcardial perfusion with $4 \%$ PFA in $0.01 \mathrm{M}$ PBS, the spinal cords were subsequently postfixed in the perfusing solution at $4^{\circ} \mathrm{C}$. Then the tissues were cryoprotected in $30 \%$ sucrose in PBS for $24-48 \mathrm{~h}$ at $4^{\circ} \mathrm{C}$. Forty micrometer sagittal cryostat sections, including the graft and spinal cord rostrally and caudally, were examined immunohistologically for the distribution of 5-HT or TH fibers at the interfaces of the PNG and beyond into the distal 
PNG+aFGF

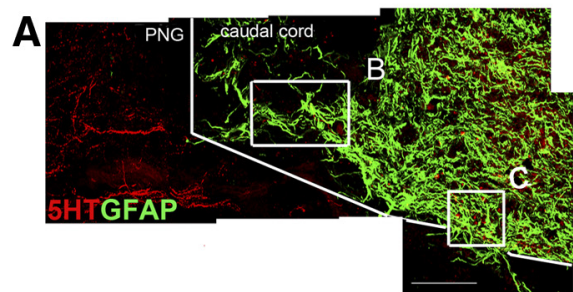

B

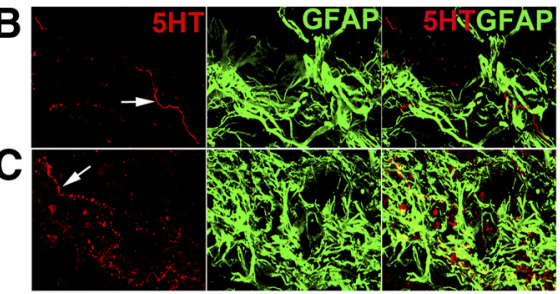

Tx-only

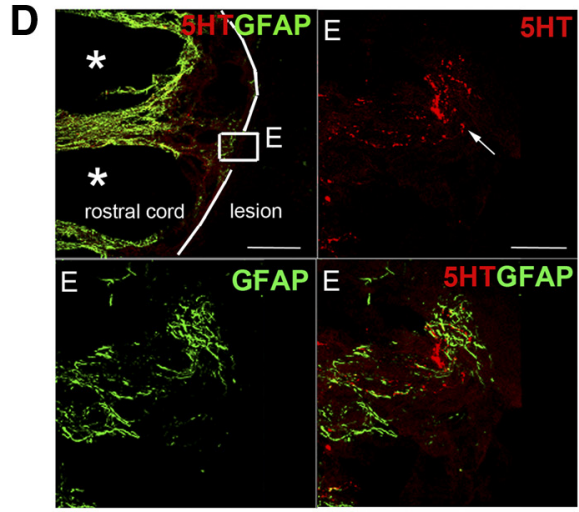

PNG+aFGF
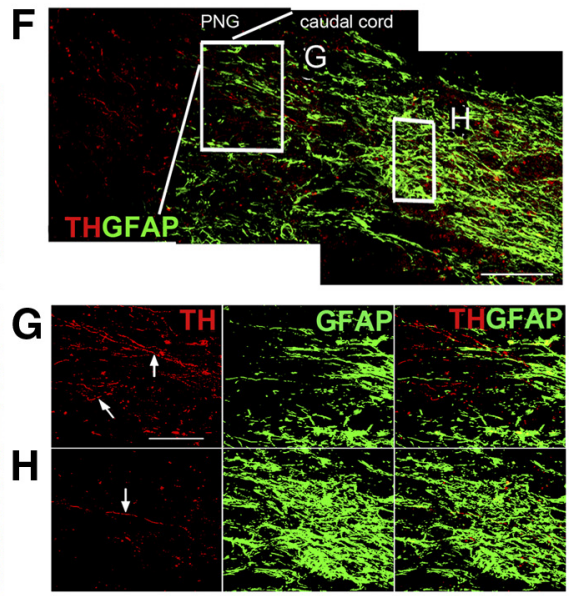

Tx-only

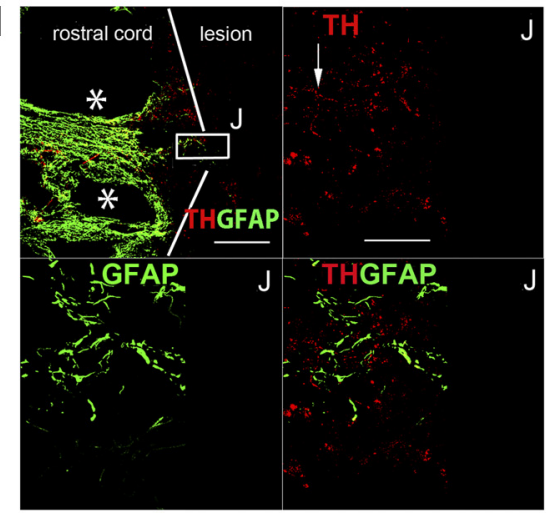

Figure 5. Axonal regeneration by PNG $+\mathrm{aFGF}$ treatment. $\boldsymbol{A}$, Representative confocal images of 5-HT immunostaining in the PNG + aFGF group showing several regenerated $5-H T$ fibers (red) growing into the caudal end of the spinal cord. The caudal spinal cord interface is demarcated by a white line. Scale bar, $200 \mu \mathrm{m} . \boldsymbol{B}, \boldsymbol{C}$, Higher-magnification images from $\boldsymbol{A}$ show identified 5-HT fibers (red, arrow) at different locations within the caudal end of the spinal cord. Scale bar, $40 \mu \mathrm{m}$. D, In the TX-only group, 5-HT fibers (red) can be identified in the rostral cord (identified by GFAP, green) but not entering the lesion cavity. The rostral spinal cord interface is demarcated by a white line. Scale bar, $500 \mu \mathrm{m} .{ }^{*}$ indicates the cavity formation in the rostral cord. $\boldsymbol{E}$, Highermagnification images from D show identified 5-HT fibers (red, arrow) at different locations within the rostral end of the spinal cord. Scale bar, $200 \mu \mathrm{m}$. $\boldsymbol{F}$, Representative confocal images of TH immunostaining in the PNG + aFGF group showing several regenerated TH fibers (red) growing into the caudal end of the spinal cord. The caudal spinal cord interface is demarcated by a white line. Scale bar, $200 \mu \mathrm{m} . \mathbf{G}, \boldsymbol{H}$, Higher-magnification images from $\boldsymbol{F}$ show identified TH fibers (red, arrow) at different locations within the caudal end of the spinal cord. Scale bar, $40 \mu \mathrm{m}$. I, In the Tx-only group, TH fibers (red) can be identified at the rostral cord (identified by GFAP, green) but not entering the lesion cavity. The rostral spinal cord interface is demarcated by a white line. Scale bar, $500 \mu \mathrm{m} .{ }^{*}$ indicates cavity formation in the rostral cord. J, Higher-magnification images from I show identified TH fibers (red, arrow) at different locations within the rostral end of the spinal cord. Scale bar, $200 \mu \mathrm{m}$

end of the spinal cord tissue. Sections were blocked in 3\% normal horse serum with $0.25 \%$ Triton X-100 in PBS for $1 \mathrm{~h}$. After blocking, sections were exposed to an anti-5-HT polyclonal antibody (1:1500 dilution; DiaSorin) with anti-glial fibrillary acidic protein (GFAP) for astrocytes (1: 500; Dako) or anti-TH polyclonal antibody (1:1000 dilution; Protos Biotechnology) with anti-GFAP antibody or anti-TH antibody with anti-synaptophysin antibody (1:200 dilution; Sigma) and then incubated overnight at $4^{\circ} \mathrm{C}$. Sections were washed, incubated with either fluorescein-conjugated or rhodamine-conjugated secondary antibody for $90 \mathrm{~min}$, washed, and coverslipped with Vectashield (Vector Laboratories). The images were collected using a Carl Zeiss LSM 510META confocal microscope.

To process cord tissue for 5-HT or TH immunohistochemistry in the lumbar area, transverse sections were blocked in 3\% normal horse serum with $0.25 \%$ Triton X-100 in PBS for $1 \mathrm{~h}$. After blocking, the sections were exposed to an anti-5-HT polyclonal antibody (1:1500 dilution; DiaSorin) or an anti-TH polyclonal antibody (1:1000 dilution; Protos Biotechnol- ogy) and incubated overnight at $4^{\circ} \mathrm{C}$. After three rinses in PBS, the sections were exposed to a biotinylated secondary antibody $(1: 200$ Vector Laboratories), followed by the $\mathrm{ABC}$ Elite kit (Vector Laboratories) for $1 \mathrm{~h}$ each. The reaction was visualized by treatment with $0.02 \% 3,3^{\prime}$-diaminobenzidine with $0.001 \%$ $\mathrm{H}_{2} \mathrm{O}_{2}$ in Tris-saline for 2-6 $\mathrm{min}$, and the sections then were examined using a light microscope.

Anatomical tracing procedures. For anterograde tracing, 2 weeks after BDA placement at the T5 level, animals were perfused with $4 \%$ PFA in PBS, and the spinal cords were collected to perform cryosectioning at $40 \mu \mathrm{m}$. Immunostaining with an anti-GFAP antibody was added to the tracer-labeled sections for doublelabeling purposes. Z-stack images were collected and compiled using a Carl Zeiss LSM 510META confocal microscope and software with a $25 \times$ objective and excitation wavelengths of 594 and $488 \mathrm{~nm}$. For retrograde tracing, a solution of tracer in normal saline [ $4 \%$ Fluoro-Gold (FG), $2 \times 2 \mu \mathrm{l}$ ] was injected carefully into both sides of the L4 spinal cord. Two weeks later, the rats were perfused, and then the brains and spinal cords were removed and sliced in the transverse plane at $40 \mu \mathrm{m}$ thickness. The slices were examined using a fluorescence microscope with ultraviolet filter.

$C M G$ and EUS EMG data analyses. The analyses of CMG pressure parameters derived from five consecutive voiding cycles collected for each animal included the time to first voiding, maximal voiding pressure, voiding interval, voiding duration, residual volume, and voiding efficiency. After the last voiding cycle and after stopping the pump infusion, the remaining saline in the bladder was collected and measured to determine the residual volume. The total volume of the bladder was measured as the bladder capacity between the beginning of saline infusion and the first leaking/micturition point, and then this value was multiplied by the saline infusion rate of $0.08 \mathrm{ml} / \mathrm{min}$. Thus, the voiding efficiency was determined as the percentage of [(total volume - residual volume)/total volume $\times 100$ ]. The EUS EMG activity during the middle phase of bladder storage, which was considered baseline activity, and bladder micturition represented by bursting activity were identified and archived in $2 \mathrm{~s}$ samples (AstroVIEW X; Astro-Med). The $2 \mathrm{~s}$ samples were filtered and smoothed as described previously with modification (Jiang et al., 2009). Briefly, the signals were rectified, and mean amplitude and firing rates were calculated after the above correction (MyosoticSignaPoint; Myosotic). In addition, the total times of EUS EMG bursting activity were measured during the voiding period. We also determined the level (by percentage) of coordination between bladder contractions and EUS bursting activity during voiding periods for the $2 \mathrm{~s}$ samples. Such coordination was defined by the alignment of the bottom part of the intraluminal pressure trace and the period of high-frequency oscillation (IPHFO) of the EUS bursting signal. Thus, the coordination level was determined as the percentage of [ (coordinated number of EUS EMG signal/total number of bottom IPHFO) $\times 100]$.

Quantitative assessment of regenerating 5- $\mathrm{HT}, \mathrm{TH}$, and anterogradely labeled nerve fibers. The numbers of 5-HT- and TH-positive fibers in various regions below the lesion/PNG (i.e., at the graft/host interface and at $250 \mu \mathrm{m}, 1 \mathrm{~mm}, 2 \mathrm{~mm}, 5 \mathrm{~mm}, 8 \mathrm{~mm}$, and $12 \mathrm{~mm}$ ) were counted under 
the microscope from all spinal-cord-injured animals. Two observers blinded to all treatment groups counted the fibers. Every 1-in-6 sections from each animal were used to count nerve fiber segments and then multiplied by 6 to represent a quantitative estimate of total numbers of fiber segments beyond the lesion per animal. The numbers of BDA-positive fibers in our anterograde tracing study were counted in several areas, including $1 \mathrm{~mm}$ rostral to the lesion/PNG, within the middle of the lesion/PNG, and at different sites caudal to the lesion/PNG (i.e., at the graft/host interface and at $250 \mu \mathrm{m}, 1 \mathrm{~mm}, 2 \mathrm{~mm}, 5 \mathrm{~mm}$, and $8 \mathrm{~mm}$ ). The section selection and the blinded method of counting fibers were the same as described above.

Statistical analyses. All data are reported as mean \pm SEM. A two-way (group $\times$ time) ANOVA followed by Tukey's post hoc ANOVA test were used to determine significant differences between groups. Linear regressions were performed using SigmaStat statistical software. Significant differences were determined at $p<$ 0.05 . All behavioral tests and data analyses were done in a blinded manner during this entire study.

\section{Results}

Multiple PNGs with aFGF/fibrin and ChABC lead to markedly improved micturition patterns in rats that had sustained complete T8 spinal cord transection

Voiding patterns were recorded with the use of metabolic cages at 3 and 6 months after spinal cord surgery. All the animals in each group were used in this study. Two main criteria, including the total number of voids over a set time and the volume per micturition, were used to make comparisons between the groups. Representative micturition patterns of sham, Tx-only, and $\mathrm{PNG}+\mathrm{aFGF}+\mathrm{ChABC}$ groups are shown in Figure $2 A$. In each "step-like" segment of the graph, the horizontal line represents the time period between individual micturition events, and the vertical lines depict the volume of urine expelled (change from baseline). At 3 months, the sham group (29 voids/16 h) showed significantly higher total numbers of voids than the spinal-cord-injured as well as the injury + treatment groups (Fig. $2 B$; $p<$ $0.05)$. However, a comparison of the six SCI groups revealed that the frequency of micturition in the $\mathrm{PNG}+\mathrm{aFGF}+$ ChABC group (13 voids/16 h) was significantly higher than the Tx-only (6 voids/16 h), PNG (7 voids/16 h), aFGF + ChABC (6 voids/16 h), PNG + ChABC (8 voids/16 h), and PNG + aFGF (8.5 voids/16 h) groups (Fig. $2 B ; p<0.05$ ). The sham group $(0.3 \mathrm{ml} /$ void $)$ also demonstrated a significantly lower volume per
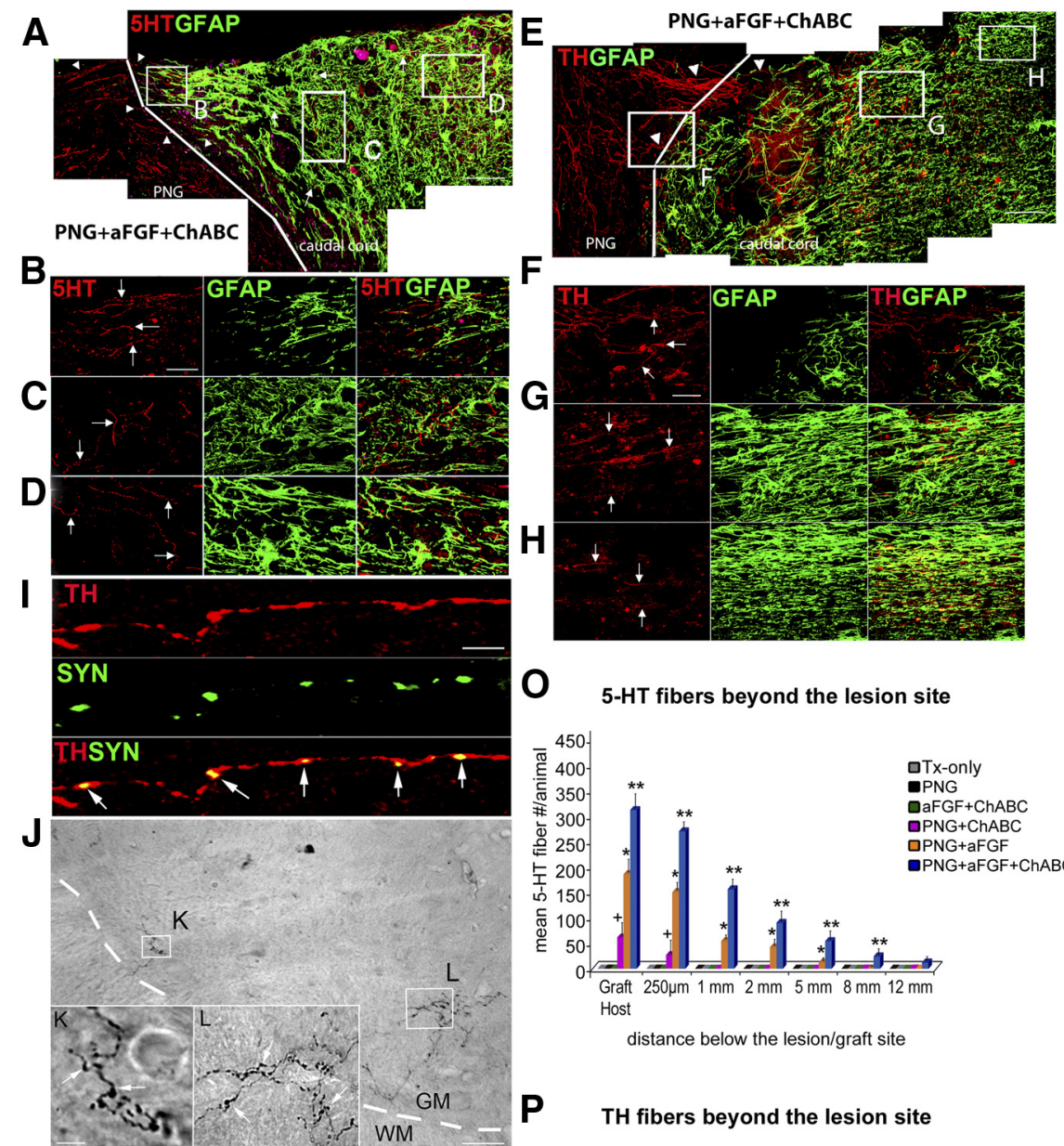

M

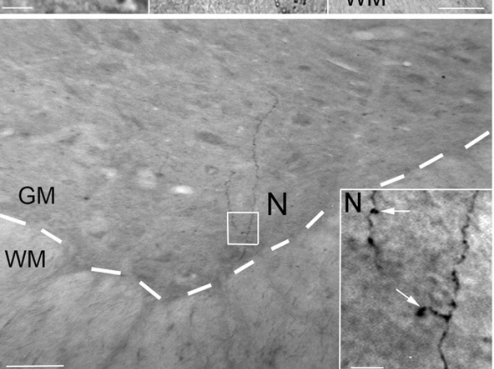

P TH fibers beyond the lesion site

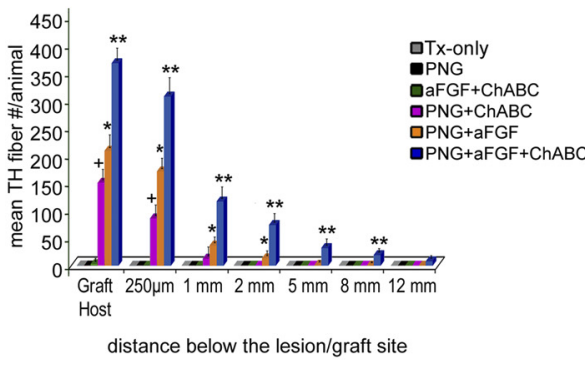

Figure 6. Significant axonal regeneration with PNG $+\mathrm{aFGF}+\mathrm{ChABC}$ treatment. The triple combination of ChABC with PNG and aFGF promotes regeneration of both 5 -HT and TH fibers beyond the PNG/caudal spinal cord interface. $A$, Confocal images of a sagittal section of the spinal cord showing that regenerated 5-HT fibers (red, white arrow head) have grown beyond the PNG (GFAP-negative area) and penetrated deep into the CNS (identified by GFAP, green). The caudal spinal cord interface is demarcated by a white line. Scale bar, $300 \mu \mathrm{m}$. $\boldsymbol{B}-\boldsymbol{D}$, Higher-magnification images from $\boldsymbol{A}$ show identified 5 -HT fibers (white arrows) at different locations within the caudal end of the spinal cord. Scale bar, $40 \mu \mathrm{m}$. Note in $\boldsymbol{A}$ the alignment of the astrocytes at a point at which axons reenter the cord. $\boldsymbol{E}$, Confocal photomicrographs of a sagittal section of the spinal cord showing that TH fibers (red, white arrow head) have regenerated beyond the graft (GFAP negative area) and well into the CNS (identified by GFAP, green). The arrowheads indicate TH fibers crossing the PNG/caudal spinal cord interface (demarcated by a white line). Scale bar, $300 \mu \mathrm{m}$. $\boldsymbol{F}-\boldsymbol{H}$, Higher-magnification images from $\boldsymbol{E}$ show identified TH fibers (white arrows) at different distances beyond the PNG/caudal spinal cord interface. Scale bar, $40 \mu \mathrm{m}$. $I$, Confocal images from immunostaining reveal a close proximity between the regenerated fibers and synapsin (SYN) puncta in PNG + aFGF + ChABC-treated animals. Doublestaining image indicates the colocalization of TH fibers and SYN (arrow). Scale bar, $70 \mathrm{~mm}$. J, Regenerated 5-HT fibers with expansive terminal arborizations were identified within the lumbar cord as depicted in this representative transverse section. Scale bar, $200 \mu \mathrm{m} . \boldsymbol{K}, \boldsymbol{L}$, Higher-magnification images from $J$. Note the bouton structures on $5-H T$ fibers (white arrow). The interface between gray matter and white matter is demarcated by a white dashed line. GM, Gray matter; WM, white matter. Scale bar, $50 \mu \mathrm{m} . M, N$, TH fibers were also identified well into the lumbar cord as shown in this representative transverse section. Note the bouton structures on $\mathrm{TH}$ fibers (white arrow). The interface between gray matter and white matter is demarcated by a white dashed line. GM, Gray matter; WM, white matter. Scale bars: $\boldsymbol{M}, 200 \mu \mathrm{m} ; \boldsymbol{N}, 50 \mu \mathrm{m}$. $\mathbf{0}$, Quantitative analysis showed greater numbers and longer-distance regeneration of $5-\mathrm{HT}$ fibers beyond the lesion in the PNG + aFGF + ChABC treatment group compared with the other SCI groups. $P$, Quantitative analysis showed more and longer-distance regeneration of TH fibers beyond the lesion in the PNG $+\mathrm{aFGF}+\mathrm{ChABC}$ treatment group versus the other $\mathrm{SCl}$ groups. ${ }^{\dagger} p<0.05$ when compared with TX-only, PNG, and aFGF + ChABC groups, ${ }^{*} p<0.05$ when compared with Tx-only, PNG, aFGF + ChABC, and PNG + ChABC groups, and ${ }^{* *} p<0.05$ when compared with Tx-only, PNG, aFGF + ChABC, PNG + ChABC, and PNG + aFGF groups. 

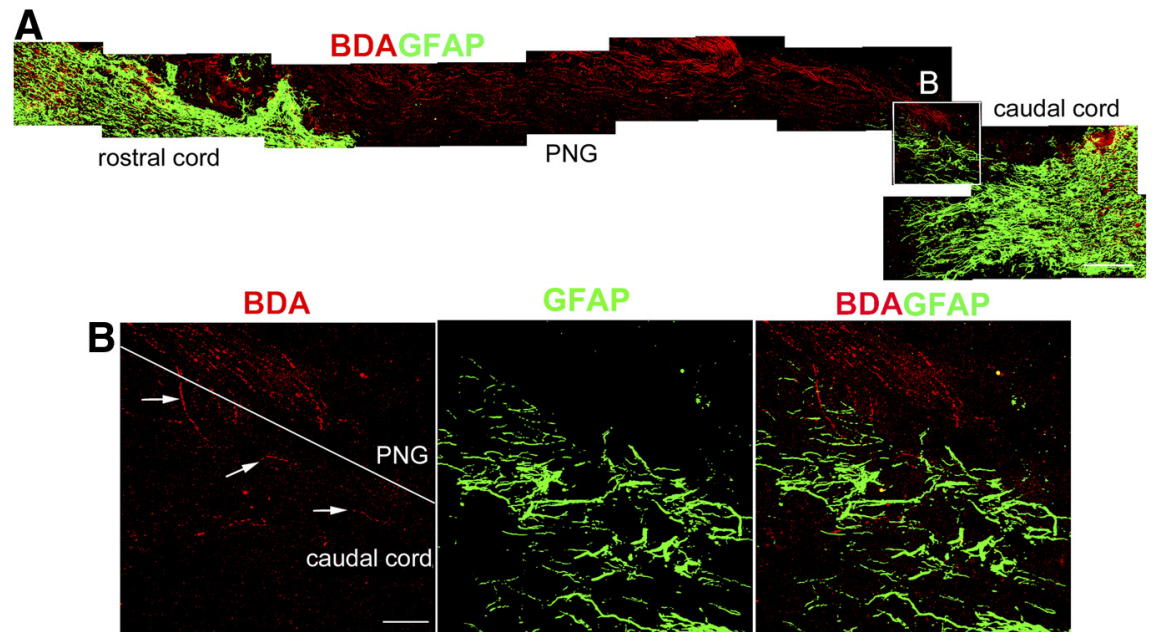

BDAGFAP

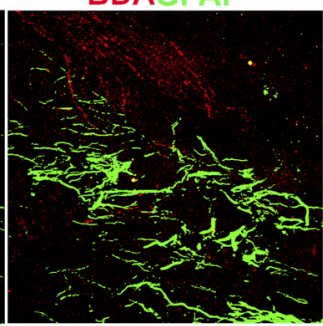

Figure 7. A few BDA-positive fibers grow beyond the graft in the PNG + aFGF animals. A, A low-magnification sagittal section shows, with the combination of BDA labeling (red) and GFAP staining (green), the overall anatomy of the PNG and spinal cord (left side is rostral and right side is caudal). Scale bar, $500 \mu \mathrm{m}$. B, High-magnification image shows a few BDA-labeled fibers (red) entering the caudal end of the spinal cord (GFAP-positive area) from PNG (GFAP-negative area). The interface of the PNG and spinal cord is demarcated by a white line. Scale bar, $100 \mu \mathrm{m}$.

micturition than all the other groups (Fig. $2 C$; $p<0.05$ ). Again, a comparison of the six SCI groups showed that the volume per micturition in the $\mathrm{PNG}+\mathrm{aFGF}+\mathrm{ChABC}$ group $(1.3 \mathrm{ml} /$ void $)$ was significantly lower than the Tx-only (2.6 ml/void), PNG (2.4 $\mathrm{ml} /$ void $),$ aFGF + ChABC (2.5 ml/void $),$ PNG + ChABC $(2.2$ $\mathrm{ml} /$ void), and the PNG + aFGF (2.1 ml/void) groups (Fig. $2 C$; $p<0.05)$. In addition, the PNG + ChABC and PNG + aFGF groups also showed significantly lower volumes per micturition when compared with the Tx-only, PNG, and aFGF + ChABC groups (Fig. $2 B, C ; p<0.05$ ).

At 6 months, the sham group still had the highest frequency (28 voids $/ 16 \mathrm{~h}$ ) and lower volume per micturition $(0.25 \mathrm{ml})$ than all six SCI groups (Fig. $2 B ; p<0.05$ ). Similar to but now much more obvious than the patterns at 3 months, the PNG + aFGF + ChABC group demonstrated a much higher frequency (18 voids/ $16 \mathrm{~h}$ ) than the Tx-only ( 5 voids/16 h), PNG (6 voids/ $16 \mathrm{~h})$, $\mathrm{aFGF}+\mathrm{ChABC}$ ( 7 voids/16 h), PNG + ChABC (10 voids/16 h), and $\mathrm{PNG}+\mathrm{aFGF}(11$ voids $/ 16 \mathrm{~h}$ ) groups (Fig. $2 B ; p<0.05)$. The complete combination group also had markedly lower volumes per micturition (1.2 $\mathrm{ml}$ ) than the Tx-only (3.2 ml), PNG (2.9 ml), $\mathrm{aFGF}+\mathrm{ChABC}(2.7 \mathrm{ml}), \mathrm{PNG}+\mathrm{ChABC}(1.9 \mathrm{ml})$, and PNG + aFGF $(1.8 \mathrm{ml}$ ) groups (Fig. $2 C ; p<0.05)$. In addition, the PNG + ChABC and PNG + aFGF groups also showed significantly higher frequency and lower volume per micturition when compared with the Tx-only, PNG, and aFGF + ChABC groups (Fig. $2 B, C ; p<0.05)$. When one compares the 6 month versus 3 month data within groups, the Tx-only, PNG, and aFGF + ChABC animals showed significantly increasing volumes per micturition over time, which is indicative of ongoing pathology within the bladder. In contrast, the PNG + aFGF + ChABC group especially, rather than declining, showed improvements in bladder function at 6 months, with more voids and lower volumes per micturition than at the 3 month time period (Fig. $2 B, C$; $p<0.05)$. In general, the metabolic cage study demonstrated that the $\mathrm{PNG}+\mathrm{aFGF}+\mathrm{ChABC}$ group had developed a more normal micturition pattern with higher-frequency micturition episodes and less voiding volume per micturition than the other five SCI groups. This indicates that the PNG + aFGF + ChABC animals did not need to store excessively large volumes of urine in the bladder to void, which is moving further toward a normal pattern.

\section{PNG with aFGF/fibrin and ChABC} markedly improves CMG and EUS EMG activity in previously spinal-cordtransected rats

Measurements of bladder contractions and EUS activity were used to further investigate the quality of bladder function at 6 months after SCI. Six animals in the sham control group, eight animals in the Tx-only group, and eight animals in each of the repaired groups were used in this investigation. During continuousinfusion CMG in sham control rats before the onset of voiding (a period when the bladder is not expelling urine), the EUS displayed low-amplitude tonic activity. There are no overt bladder contractions before the voiding event (see a typical bladder pressure trace of sham animals in Fig. $3 A$ ). The tonic EUS activity increases in amplitude at the onset of micturition and then (peculiar to rats) rises precipitously to a large-amplitude bursting pattern during the voiding period (see a typical EUS EMG trace of sham animals in Fig. 3A). The "ramp-like" pairs of dashed lines on both bladder pressure and EUS EMG recordings indicate the point during the voiding event from which a greatly expanded portion of the trace is depicted. At the micturition point, the sham group demonstrates the coordination that normally occurs during the micturition cycle between bladder contractions and EUS EMG bursting patterns (Fig. $3 A$ ). At 6 months after T8 spinal cord complete transection, there was significant DSD that was displayed as large-amplitude non-voiding contractions and atypical EUS EMG bursting activity during the voiding attempt (both bladder pressure trace and EUS EMG trace of Txonly in Fig. 3A). The PNG, aFGF + ChABC, and PNG + ChABC groups (Fig. $3 A$ ) had similar maladaptive patterns of bladder pressure and EUS EMG activity. Although the PNG + aFGF group (Fig. 3A) showed somewhat diminished amplitudes of non-voiding bladder contractions, with partial EUS EMG bursting activity during voiding, there was no coordination between the EUS and bladder contractions during micturition. In contrast to all the other treated SCI groups, the PNG + aFGF + ChABC group (Fig. $3 A$ ) showed the greatest reduction in frequency of DSD as well as much reduced amplitudes of non-voiding bladder contractions. In addition, and rather remarkably, the PNG + aFGF + ChABC group also demonstrated the characteristic phasic EUS EMG bursting activity that was well coordinated with bladder contractions during voiding.

The CMG analyses also showed that the PNG + aFGF + ChABC group (at $39.8 \mathrm{~min}$ ) had the shortest time to the first void $(p<0.05$; Fig. $3 B)$ among all the SCI groups (the others were $54.6-75.4 \mathrm{~min}$ ). The sham group waited $9.4 \mathrm{~min}$ to first void. The residual volume (Fig. $3 B$ ) in the PNG + aFGF + ChABC group $(1.5 \mathrm{ml})$ was the lowest amount $(p<0.05$; Fig. $3 B)$ compared with other SCI groups (the others were $2.7-4.1 \mathrm{ml}$ ), whereas the sham group was $0.03 \mathrm{ml}$. The maximal voiding pressure (Fig. $3 B$ ) in the $\mathrm{PNG}+\mathrm{aFGF}+\mathrm{ChABC}$ group $\left(43.2 \mathrm{~cm} \mathrm{H}_{2} \mathrm{O}\right)$ was significantly lowest $(p<0.05)$ among all SCI groups (the others were $52.5-54.3 \mathrm{~cm} \mathrm{H}_{2} \mathrm{O}$ ), whereas the sham group was $41.2 \mathrm{~cm} \mathrm{H}_{2} \mathrm{O}$. The voiding efficiency (Fig. $3 B$ ) in the PNG + aFGF + ChABC 


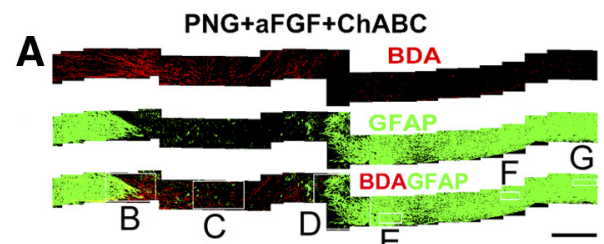

\section{D}
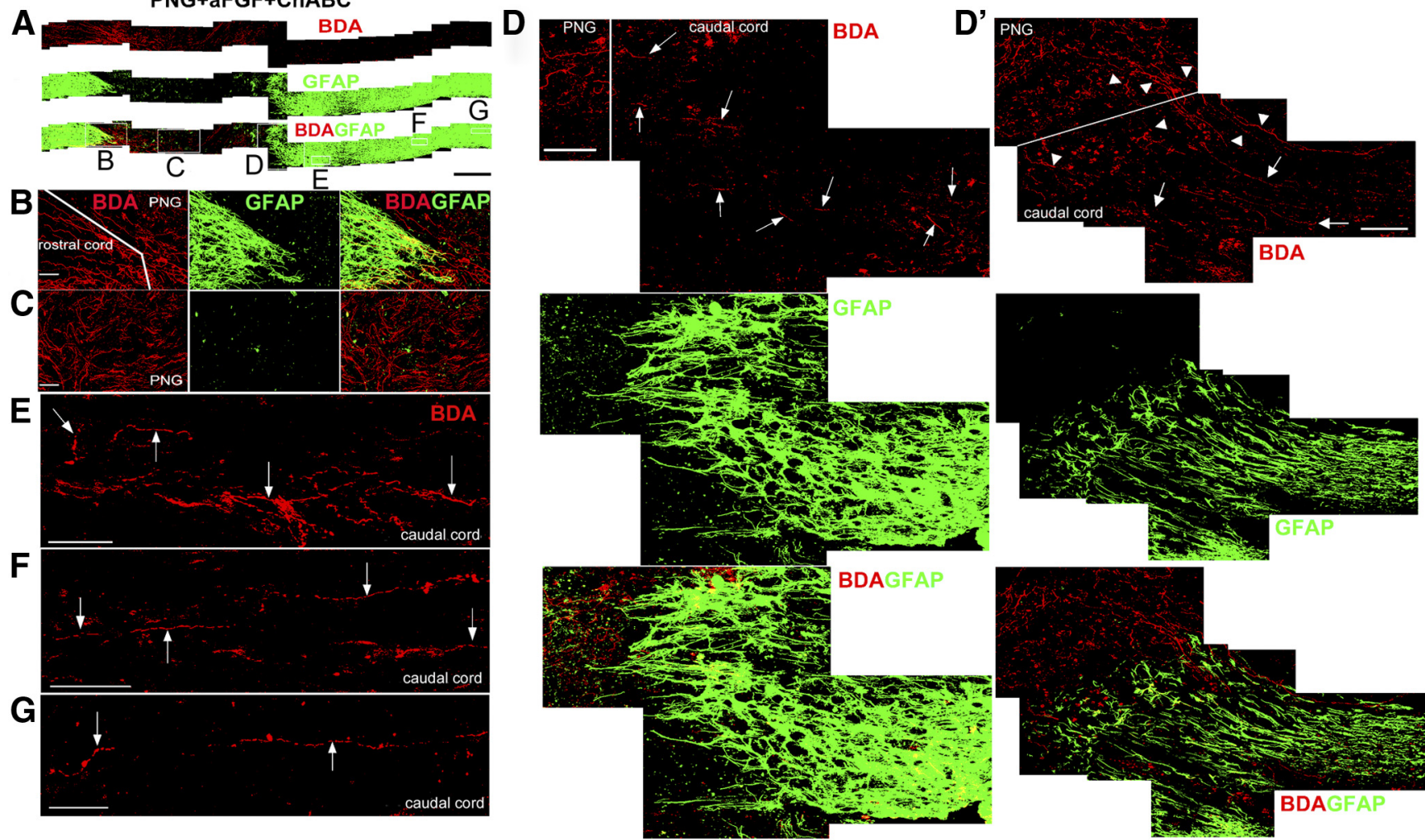

H

Quantitative distribution of BDA labeled fibers

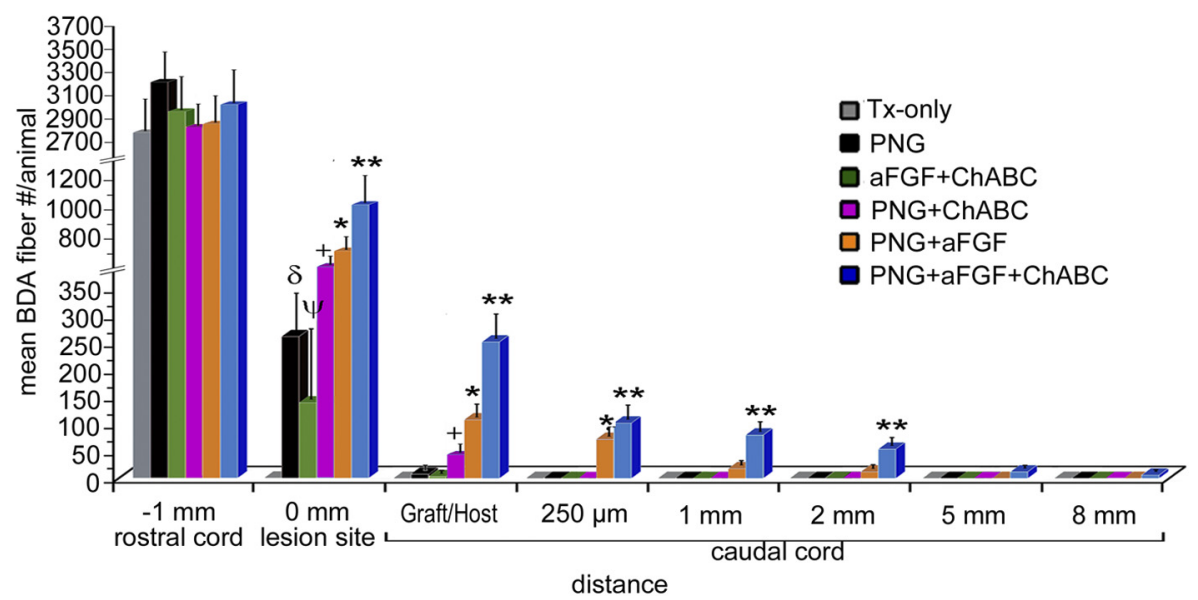

Figure 8. Anterograde tracing to label regenerating axons in the PNG $+\mathrm{aFGF}+\mathrm{ChABC}$ treatment group. $A$, These three low-magnification sagittal sections of confocal images show with BDA labeling (red) and GFAP staining (green) and the two combined, the overall anatomy of the PNG and spinal cord (left side is rostral and right side is caudal). Scale bar, $1000 \mu \mathrm{m}$. $\boldsymbol{B}$, High-magnification confocal image shows the large number of BDA-labeled fibers (red) entering the PNG (GFAP negative area) from the rostral end of the spinal cord (GFAP-positive area). The interface of the PNG and spinal cord is demarcated by a white line. Scale bar, $100 \mu \mathrm{m}$. Significant numbers of BDA-labeled fibers were identified within the PNG ( $C$ ) and penetrating deeply into the interface of the PNG with the caudal end of the spinal cord (D) (demarcated by a white line). Note the alignment of the GFAP-positive astrocyte processes. $\boldsymbol{D}^{\prime}$, An adjacent section to $\boldsymbol{D}$ showing more evidence of the BDA-labeled fibers (red and arrowheads) crossing the PNG/caudal spinal cord interface. $\boldsymbol{E}-\mathbf{G}$, The BDA-labeled fibers (red, white arrows) were identified at various locations continuing far caudally into the spinal cord. Scale bar, $50 \mu \mathrm{m}$. H, Quantitative analysis showed greater numbers and longer-distance penetration of BDA-labeled fibers beyond the lesion in the PNG + aFGF + ChABC treatment group than the other SCI groups. ${ }^{\delta} p<0.05$ when compared with Tx-only and aFGF + ChABC groups, ${ }^{\psi} p<0.05$ when compared with Tx-only group, ${ }^{\dagger} p<0.05$ when compared with Tx-only, PNG, and aFGF + ChABC groups, ${ }^{*} p<0.05$ when compared with Tx-only, PNG, aFGF + ChABC, and PNG + ChABC groups, and ${ }^{* *} p<0.05$ when compared with Tx-only, PNG, aFGF + ChABC, PNG + ChABC, and PNG + aFGF groups.

group (82\%) was the highest amount $(p<0.05)$ compared with the other SCI groups $(48-67 \%)$, whereas the sham group was $98.2 \%$. The voiding duration (Fig. $3 B$ ) in the PNG + aFGF + ChABC group $(43.9 \mathrm{~s})$ was clearly the longest $(p<0.05)$ compared with other SCI groups (which were 27.5-33.6 s), whereas the sham group was $42.1 \mathrm{~s}$. The voiding interval (Fig. 3B) in the PNG + ChABC, PNG + aFGF, and PNG + aFGF + ChABC groups $(8.8-10.1 \mathrm{~min})$ was again the longer $(p<0.05)$ compared with the Tx-only, PNG, and aFGF + ChABC groups (1.9-2.3 $\mathrm{min}$ ), whereas the sham group was $8.9 \mathrm{~min}$. Together, the CMG data indicate that the cord-injured animals treated with a combination of PNG + aFGF + ChABC demonstrated far less bladder incontinence and distension as well as fewer non-voiding bladder contractions, indicating a reduction of bladder hyperreflexia. 
A
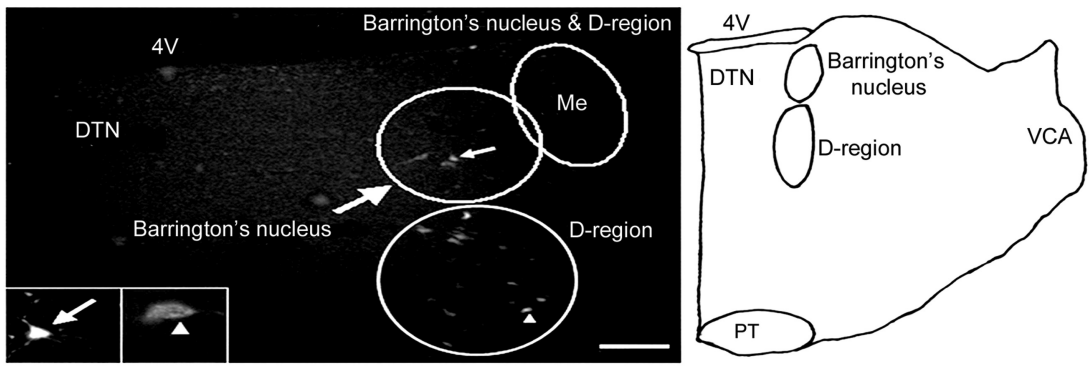

B
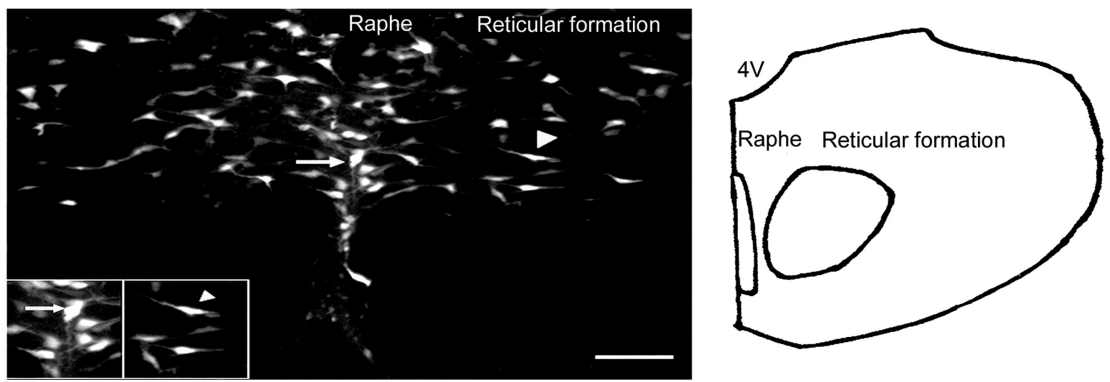

C

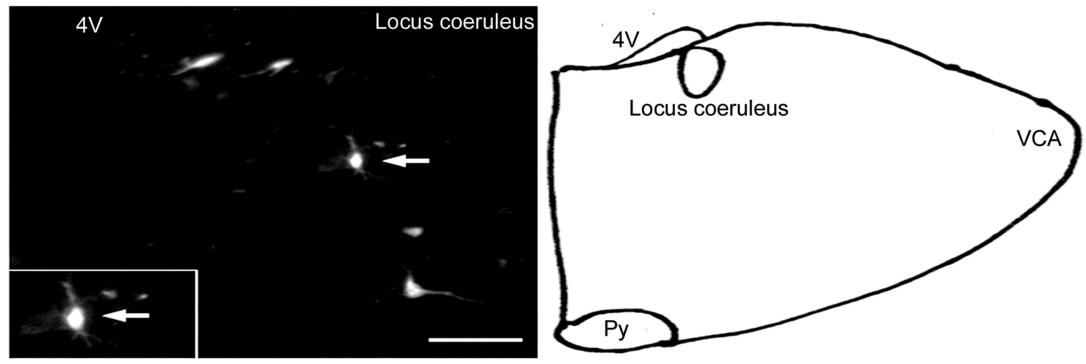

D

Retrogradely labeled FG-cells number from tracing study

\begin{tabular}{lccccc}
\hline & Barrington's nucleus & D-region & Locus coeruleus & Raphe & Reticular formation \\
\hline sham & $529 \pm 26.1$ & $826 \pm 42.5$ & $638 \pm 89.2$ & $793 \pm 125.6$ & $1269 \pm 174.1$ \\
Tx-only & 0 & 0 & 0 & 0 & 0 \\
PNG & 0 & 0 & 0 & 0 & 0 \\
aFGF+ChABC & 0 & 0 & 0 & 0 & 0 \\
PNG+ChABC & 0 & 0 & 0 & $4+1.5^{*}$ & $9 \pm 3.3^{*}$ \\
PNG+aFGF & 0 & $6 \pm 1.2^{*}$ & 0 & $7+4.7^{*}$ & $12 \pm 2.6^{*}$ \\
PNG+aFGF+ChABC & $8 \pm 2.3^{* *}$ & $19 \pm 8.6^{* *}$ & $14 \pm 3.3^{* *}$ & $21+8.1^{* *}$ & $101 \pm 28.4^{* *}$ \\
\hline
\end{tabular}

Figure 9. Retrograde anatomical tracing indicated the neuronal populations that have regenerated axons below the lesion site in the PNG + aFGF + ChABC treatment group. $\boldsymbol{A}$, FG-labeled cells were identified in the pontine micturition center, including Barrington's nucleus (arrow) and D region (arrowhead). Scale bar, $800 \mu \mathrm{m}$. B, FG-labeled cells were identified in both raphe nuclei (arrow) and the reticular formation (arrowhead). Scale bar, $400 \mu \mathrm{m}$. C, The retrogradely FG-labeled neurons (arrow) could be identified in locus ceruleus. Scale bar, $250 \mu \mathrm{m}$. D, Quantification of the FG-labeled cells in the retrograde tracing study. Me, Mesencephalic nucleus of trigeminal nerve; DTN, dorsal tegmental nucleus; $4 \mathrm{~V}$, fourth ventricle; VCA, ventral cochlear nucleus, anterior; Py and PT, pyramidal tract. * $p<0.05$ when compared with Tx-only, PNG, and aFGF + ChABC groups, and ${ }^{* *} p<0.05$ when compared with Tx-only, PNG, aFGF + ChABC, PNG + ChABC, and PNG + aFGF groups.

The EUS EMG analyses revealed that $100 \%$ of the animals in the sham group showed the presence of EUS EMG bursting activity during voiding. Seventy percent of the animals among all the SCI groups had some sort of EUS EMG activity as well. However, the duration of EUS EMG bursting in the PNG + aFGF + ChABC group $(3.8 \mathrm{~s})$ was significantly longer $(p<0.05)$ than the other SCI groups (which were $0.8-2.2 \mathrm{~s}$ ), whereas the sham group was $5.6 \mathrm{~s}$ (Fig. 3C). In addition, overall coordination between bladder contractions and EUS bursting during voiding in the PNG + aFGF + ChABC group (85\%) was significantly higher than the other SCI groups (which were 55-70\%). There were no significant differences in the EUS EMG bursting amplitudes among the groups (Fig. 3C). The firing rate of EMG bursting in the PNG + aFGF + ChABC group $(297 \mathrm{~Hz})$ was significantly lower $(p<0.05)$ than the other SCI groups (380-596 Hz), whereas the sham was 177 $\mathrm{Hz}$ (Fig. 3C). In general, the PNG + aFGF + $\mathrm{ChABC}$ treatment provides significant recovery of EUS EMG activity, allowing for better coordination with bladder contractions. All the aforementioned measurements are indicative of a reduction of DSD and higher efficiency of micturition control in the full-combination treatment animals, with some indicators achieving normal or near-normal levels. Additional improvements in urinary function beyond that at 6 months were not seen in three animals at 9 months after lesion and treatment with the full-combination therapy.

\section{PNG + aFGF + ChABC treatment improves bladder morphology}

Because of the need to store abnormally large amounts of urine, SCI animals display considerably increased bladder sizes and weights than in sham animals at 6 months after complete spinal cord transection. The bladder wall of the Tx-only, $\mathrm{PNG}$, and aFGF + ChABC groups had developed edematous connective tissue with extensive proliferation of the urothelial layers facing the lumen (Fig. $4 A-N$ ). The $\mathrm{PNG}+\mathrm{aFGF}$ and the PNG + ChABC groups, but especially the PNG + aFGF + ChABC group, showed much less tissue edema and less proliferation of the urothelial layers, resulting in significantly less total bladder weight (Fig. 4O).

\section{Evidence of regeneration and synapse formation by 5 -HT and TH fibers} crossing the PNG/caudal spinal cord interface

Given the improvements in voiding behavior in rats that received the ChABC + PNG + aFGF treatment, we next examined whether axonal regrowth could extend beyond the caudal interface between the PNG and spinal cord. Immunostaining demonstrated in PNG + aFGF (Fig. 5A-C,F-H), PNG + ChABC (data not shown), and especially PNG + aFGF + ChABC (Fig. $6 A-J)$ groups that both $\mathrm{TH}$ - and 5-HT-positive fibers (these systems are important in controlling micturition) had extended into the bridge, across the caudal PNG/spinal cord interface and well into the caudal cord (the CNS compartment was demarcated by the presence of GFAP). 5-HT- and TH-positive fibers were identified only in the rostral penumbra of the lesion in the Tx-only group (Fig. $5 D, E, I, J)$. There was absolutely no evidence that $\mathrm{TH}$ or 5-HT fibers had crossed into the caudal cord beyond the lesion in the PNG and aFGF + ChABC groups. Interestingly, precisely at the interface between the PNG and CNS tissue (especially in the additionally aFGF- or ChABC-treated or both treated animals), 
there often occurred a rectilinear alignment of the astrocytes and at these points axons appear to have gained access to the distal cord. For example, in Figure 5A, axons reenter the cord at a dorsal location through a zone of aligned astrocytes instead of more ventrally in which there was a more "wall-like" arrangement (Fig. 6A). Importantly, there were far greater numbers of regenerated 5-HT or TH axons and regenerated axons that traveled longer distances beyond the graft site to lumbar levels in the PNG + aFGF + ChABC group (Fig. $6 J-N$ ) than in the PNG + ChABC and PNG + aFGF groups.

With the use of double labeling, it was apparent that regenerated fibers that entered the distal end of the spinal cord could express synapse-associated proteins, suggesting the possibility of functional reconnection (Fig. 6I). Overall, detection of considerable numbers of 5-HT and TH fibers growing far beyond the interface of the PNG/caudal spinal cord in the PNG $+\mathrm{aFGF}+\mathrm{ChABC}$ group (for a quantitative analysis, see Fig. 6O,P) is consistent with their possible involvement in the improvement of bladder function.

\section{Anterograde and retrograde labeling of regenerating neurons}

BDA for anterograde tracing was placed at a fresh transection site at $\mathrm{T} 5$, which was above the original transection site (T8).

No BDA-labeled fibers were found beyond the caudal end of the bridge in any of the Tx-only, PNG, and aFGF + ChABC animals. The PNG animals showed BDA-labeled fibers growing into but not exiting the graft (data not shown). There were scattered fibers just beyond the graft in the PNG + aFGF group (Fig. 7), as well as the PNG + ChABC group (data not shown). Remarkably, the PNG + aFGF + ChABC animals (Fig. $8 A-G$ ) had substantial regeneration into and beyond the graft. Confocal reconstructions and quantitative analysis (Fig. $8 \mathrm{H}$ ) confirmed that regenerated fibers had penetrated deeply into the gray matter near the PNG/ caudal spinal interface, and many were identified in the white matter traveling several millimeters farther down the cord, with a few making it to the very end of our sections.

Retrograde tracing by injecting FG into the spinal cord (at approximately L4; nearly $2 \mathrm{~cm}$ below the rostral graft site) was used to further determine the neural populations that may contribute to nerve regeneration well beyond the bridge/cord interface. In the Tx-only, PNG, and aFGF + ChABC groups, there were no FG-labeled neurons anywhere in the rostral cord or brain. In contrast, FG-labeled neurons could be clearly identified within different regions and in several nuclei in the PNG + ChABC, PNG + aFGF, and PNG + aFGF + ChABC groups, with far more in the triple-combination animals. The PNG + aFGF + ChABC group showed FG-labeled cells in the all important pontine micturition center (Barrington's nuclei and the D-region), as well as the locus ceruleus, nuclei raphe magnus, and the reticular formation (gigantocellular reticular nuclei) (Fig. 9A-C). Besides FG-labeled cells in the brain, the cervical and thoracic spinal cord also contained labeled cells likely to be part of the propriospinal system. The PNG + aFGF and PNG + ChABC groups also showed a few labeled cells in the D-region, raphe magnus nuclei, reticular formation, and the cervical spinal cord. Importantly, the PNG $+\mathrm{aFGF}+\mathrm{ChABC}$ group contained far more FG-labeled cells and in more neural populations than did the PNG + ChABC or PNG + aFGF groups (Fig. 9D).

\section{Effects of re-transecting the cord in animals with and without repair bridges}

Animals in all SCI groups (five animals in each group) were used to perform spinal cord re-transection at the T5 level. They were reevaluated for bladder function 2 weeks later. In the Tx-only, PNG, aFGF + ChABC, and PNG + ChABC groups, there were no or only minor differences in their already abnormal overnight micturition patterns after spinal cord re-transection (Fig. 10A). There also were no significant differences in both CMG/EUS EMG parameters after spinal cord re-transection, including EUS bursting activity during voiding in the non-regenerating groups, but there were some changes in the relatively poorly regenerating groups (Fig. 11 A,B). CMG analysis in the PNG + ChABC group did show significant increases in the time to first void and decreases in voiding intervals $(p<0.05)$, but there was no difference in EUS EMG analysis after spinal cord re-transection. Metabolic cage analyses of the PNG + aFGF group showed significant differences $(p<0.05)$ in increased volume per micturition but not in voiding frequency after spinal cord re-transection (Fig. 10A). CMG and EUS EMG analysis showed continuing in- 


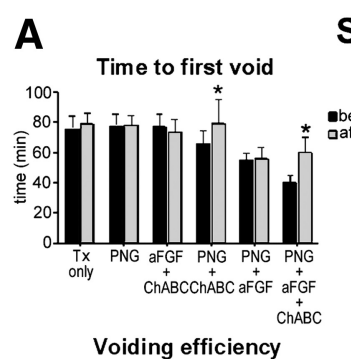

Spinal cord re-transection

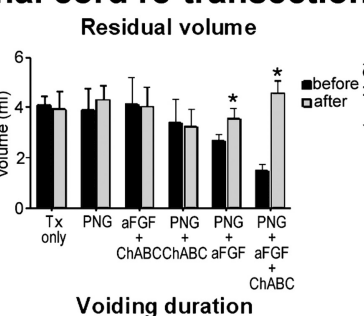

Maximal voiding pressure
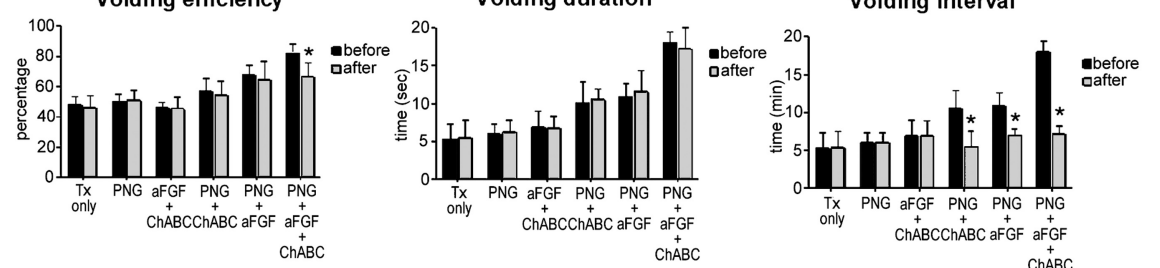

B Number of animals with EUS

bursting during voiding
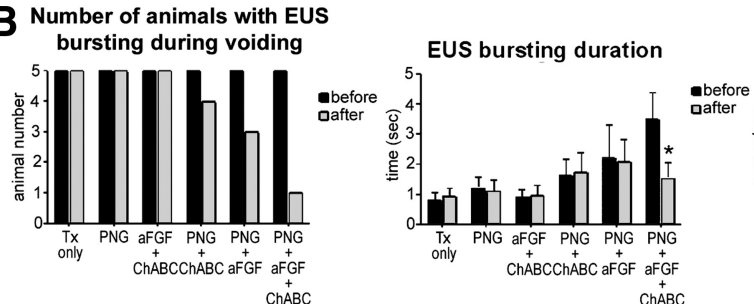

Coordination of EUS bursting with bladder contraction

100
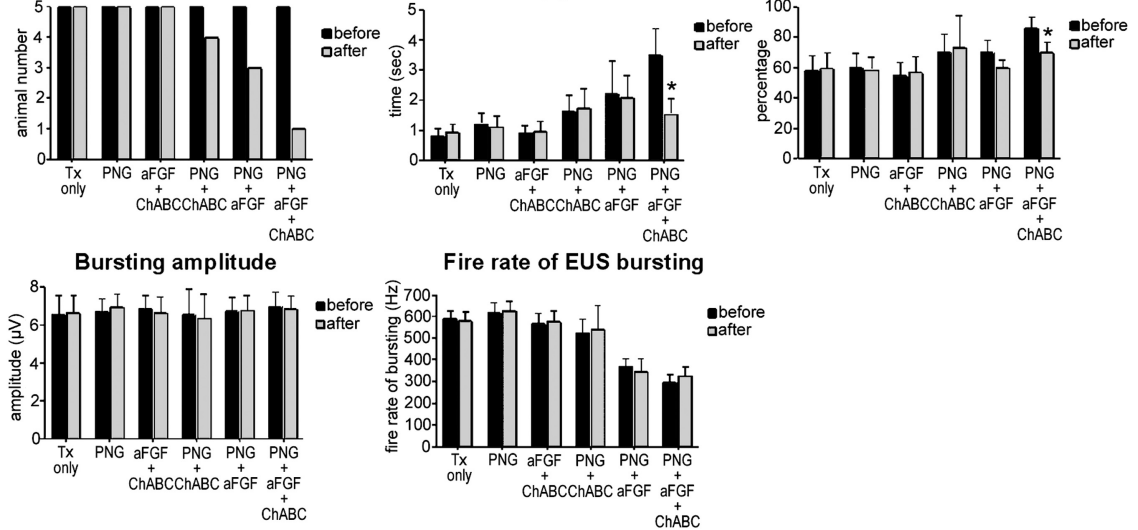

Figure 11. CMG and EUSEMG analysis after spinal cord re-transection. $\boldsymbol{A}$, There was no significant difference in CMG parameters after spinal cord re-transection in the Tx-only, PNG, and aFGF + ChABC groups. The PNG + ChABC group showed increased times to first void and decreased voiding intervals after re-transection. The PNG + aFGF group showed significant increases in residual volume and decreases in voiding intervals after re-transection. The PNG + aFGF + ChABC group showed greatly increased times to first void, increased maximal voiding pressures, increased residual volumes, decreased voiding efficiency, and decreased voiding intervals after re-transection. $B$, Spinal cord re-transection does not alter EUS EMG parameters in Tx-only, PNG, aFGF + ChABC, PNG + ChABC, and PNG + aFGF groups. The PNG + aFGF + ChABC group showed elimination of the reacquired, patterned EUS bursting activity, decreased EUS bursting lengths, and no coordination between bladder contractions with EUS bursting after spinal cord re-transection. ${ }^{*} p<0.05$ when compared with the before treatment.

creases in residual volume, decreases in voiding intervals, and, as before, no EUS bursting activity after spinal cord re-transection (Fig. $11 A, B ; p<0.05$ ). The PNG + aFGF + ChABC group displayed the most significant declinations in regained urinary function after re-transection, with markedly decreased voiding frequency as well as increased volume per micturition (Fig. 10A). CMG and EUS EMG analyses showed greatly increased times to first void, increased maximal voiding pressures, increased residual volumes, decreased voiding efficiency, decreased voiding intervals, complete elimination of the reacquired, patterned EUS bursting activity, decreased EUS bursting lengths, and no coordination between bladder contractions and EUS bursting (Figs. $10 B, 11 A, B ; p<0.05)$.

\section{Effects of pharmacological blockade on bladder recovery}

Because there was abundant 5-HT and TH regeneration in the full-combination animals, we used pharmacological blockade to investigate the contribution of the 5-HT and TH systems in the recovery of bladder function. During 5-HT receptor blockade, the $\mathrm{PNG}+\mathrm{aFGF}+\mathrm{ChABC}$ group displayed the most significant differences after perturbing 5-HT function with decreased voiding frequency but, interestingly, without changes in the volume per micturition (Fig. 12A). There were increases in the time to first void, decreased voiding intervals, and decreases in the coordination between bladder and sphincter attributable to reduction of EUS bursting activity (Figs. 12B, 13A,B; $p<$ 0.05). After $\alpha$-methyl-DL-tyrosine application (TH depletion), the PNG + aFGF + ChABC group reverted back significantly (but importantly not completely) to the transection state with decreased voiding frequency as well as increased volume per micturition (Fig. 12C). CMG and EUS EMG analyses showed significantly increased time to first void, increased maximal voiding pressure, increased residual volume, decreased voiding intervals, elimination of EUS bursting activity, decreased EUS bursting length, and decreased coordination between bladder contractions and EUS bursting (Figs. 12D, 14A, B; $p<0.05$ ). In general, the aforementioned perturbations provide evidence that regained control of micturition is, indeed, brought about via regeneration of certain critical supraspinal inputs to the caudal cord.

\section{Discussion}

The results of this investigation have demonstrated the feasibility of reestablishing functional connections via regeneration, after T8 complete transection in adult rats, between various brainstem nuclei, including the pontine micturition center and the circuitry within the lumbo-sacral cord that controls proper behavior of the lower urinary tract. The combination of $\mathrm{PNG}+\mathrm{aFGF}+\mathrm{ChABC}$ treatments lead to a markedly improved quality of daily voiding patterns, diminished DSD, enhanced voiding efficiency, as well as improved bladder morphology. We also demonstrate for the first time that some injured axons emanating from certain populations of neurons in the brainstem as well as the propriospinal system can slowly regrow for remarkably long distances $(\sim 2 \mathrm{~cm})$ once they are guided in this manner past the inhibitory environment of the glial scar. Re-transection of the cord abolished restored function, strongly suggesting that regeneration was critical to the improvements in micturition.

In the current study, all non-regenerating groups of animals displayed significant detrusor hyperreflexia at 6 months after complete SCI. In the triple-combination animals especially, the marked reduction in both frequency and amplitude of non-voiding contractions as well as the production of far lower maximal voiding pressures were likely attributable to regeneration of specific brainstem fiber pathways. An understanding of which particular centers were responsible for the various aspects of improved bladder function is important because we need to target them as we move forward with improved regeneration strategies in the future. Several studies indicate that $\beta 3$-adrenergic receptor agonists can relax detrusor smooth 
muscle in rats (Woods et al., 2001; Frazier et al., 2006). Because pharmacological blockade of TH synthesis mostly eliminated the improvements in detrusor hyperreflexia, this points to the important contribution of regenerated $\mathrm{TH}$ fibers (some of which were likely adrenergic) in the reduction of abnormal bladder wall activity.

Poor-quality EUS bursting activity, which can lead to some ability to urinate, albeit abnormally, can slowly return in rats after mid-thoracic complete spinal cord transection as was demonstrated with the present data and which confirms other studies (Cheng and de Groat, 2004; Leung et al., 2007). This is likely attributable to synaptic plasticity in the vicinity of the central pattern generator for reflex EUS bursting activity that has been discovered near the L4 level (Chang et al., 2007). Indeed, in the present study, spinal cord re-transection at 6 months did not affect the irregular patterns of EUS bursting that had developed in the Tx-only, PNG, and aFGF + ChABC groups, with no evidence of nerve regeneration through the lesion site. The application of $5-\mathrm{HT}_{1 \mathrm{~A}}$ receptor agonists as well as $\beta 2 / 3$ adrenoceptor agonists has been shown to improve EUS activity and voiding efficiency (Morita et al., 2000; Dolber et al., 2007), and, indeed, the quality of the returned, more regularly patterned EUS bursting particularly in the PNG + aFGF + ChABC group was degraded but, importantly, not completely eliminated via pharmacological applications that block both 5-HT and TH. This indicates that these particular reformed supraspinal inputs, but also other regenerating pathways likely from the pontine micturition center or reticular formation, may directly foster recovery or indirectly help regulate neuroplasticity and allow the animal to regain control of this critical sphincter.

Why did this particular combination therapy allow for such robust axonal regeneration well beyond that of our previous studies (Houle et al., 2006; Alilain et al., 2011) in which we used ChABC and single, longer bypass PNS bridges that were directed just above ventral horn gray matter? We suggest that maximizing surface area with the use of multiple grafts coupled with the enzyme effectively increases access to the distal white matter, which, in turn, can permit longdistance regeneration (Davies et al., 1997, 1999; Silver and Miller, 2004; Gensel et al., 2009; Lu et al., 2012b). In addition, the use of FGF may have a variety of beneficial synergistic effects. The FGF family members have multiple functions, including their capacity to modulate cell proliferation, migration, differentiation, and survival (Teng et al., 1998; Rabchevsky et al., 2000; Lee et al., 2006). Previous work using organotypic slice cultures (Lee et al., 2002a) and an in vivo SCI model combining aFGF with a PNG
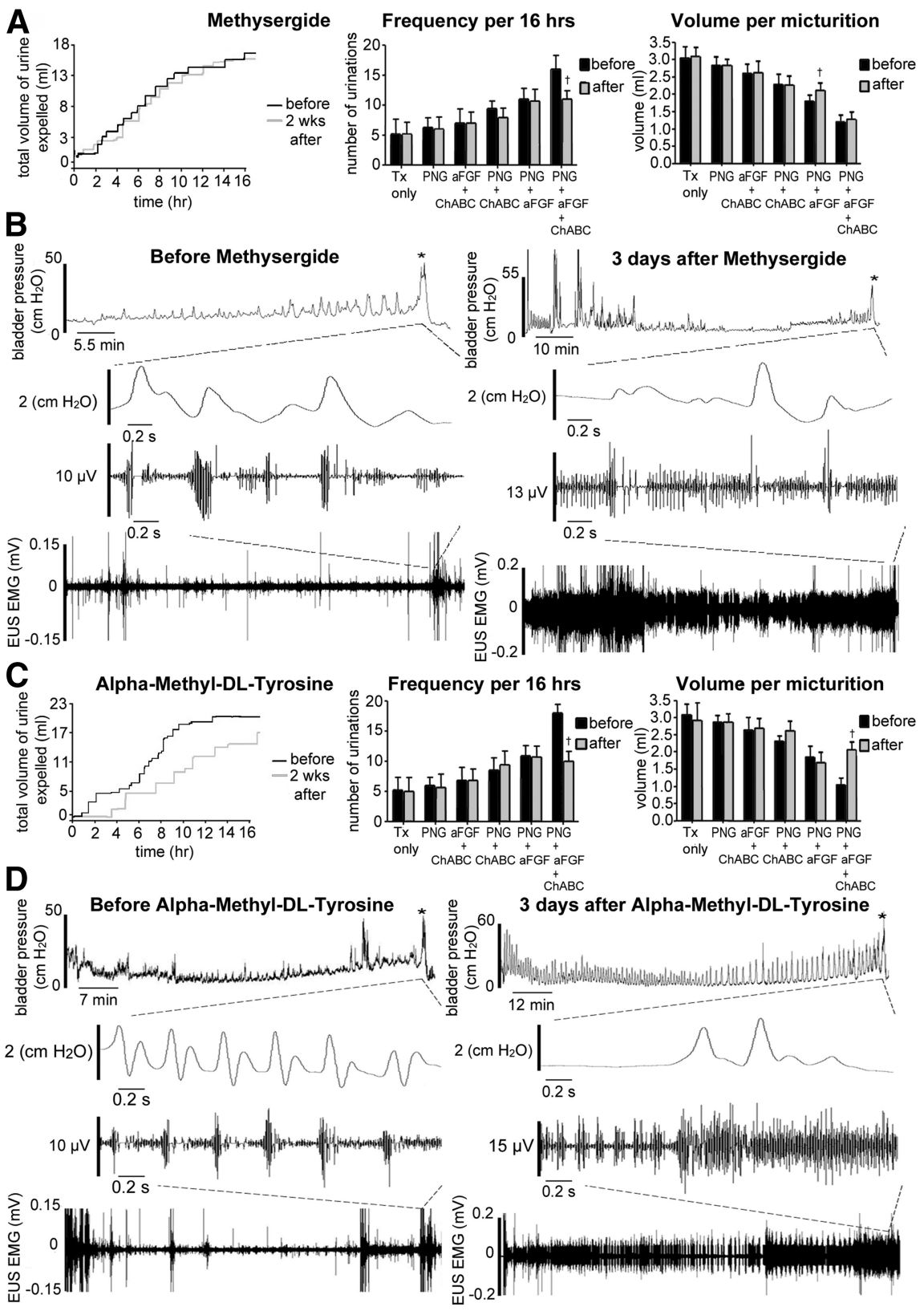

Figure 12. Pharmacological manipulations eliminate or reduce the improvements in bladder function after regeneration. $\boldsymbol{A}$ Raw data of a representative PNG + aFGF + ChABC-treated animal at $3 \mathrm{~d}$ after methysergide application. The micturition patterns returned to lower frequencies of voiding, but there was no difference in volume per micturition. $\boldsymbol{B}$, Coordination between bladder contractions and EUS EMG bursting activity during voiding was diminished, but no significant differences occurred in the amplitudes of non-voiding contractions. C, Raw data of a representative PNG + aFGF + ChABC-treated animal at 3 d after $\alpha$-methylDL-tyrosine application, the micturition patterns returned to lower frequencies of voiding and higher volumes per micturition. $\boldsymbol{D}$, Amplitudes of non-voiding bladder contractions increased, and coordination between bladder contractions and EUS EMG bursting activity during the voiding period was eliminated. ${ }^{\dagger} p<0.05$ when compared with the before treatment.

(Cheng et al., 1996; Lee et al., 2002b; Tsai et al., 2005) has shown the important role of aFGF in enhancing axonal regeneration. In other studies, aFGF was demonstrated to promote axonal regeneration and reduce death of neurons after SCI or brain ischemia (Russell et al., 2006). In addition, FGF has been shown to be a supportive molecular enhancer of long-distance, unbranched axon regrowth from adult DRG transplants across the corpus callosum (Jin et al., 2008; Ziemba et al., 2008). Therefore, the application of aFGF in our repair strategy is important not only to facilitate axonal growth in general but also to help allow axons to grow straight, especially at the entrances and exits of the PNG. 


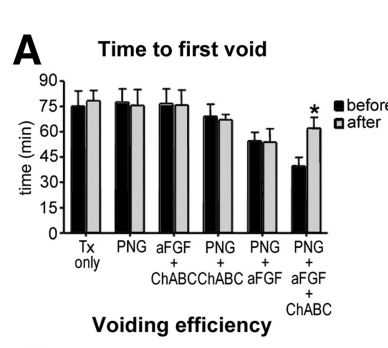

Methysergide application

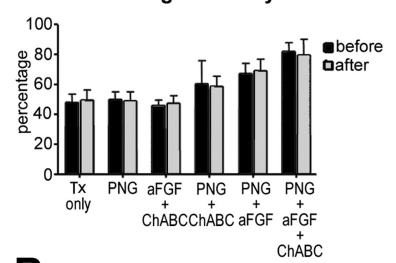

$\stackrel{+}{\mathrm{ChABC}}$

B Number of animals with EUS
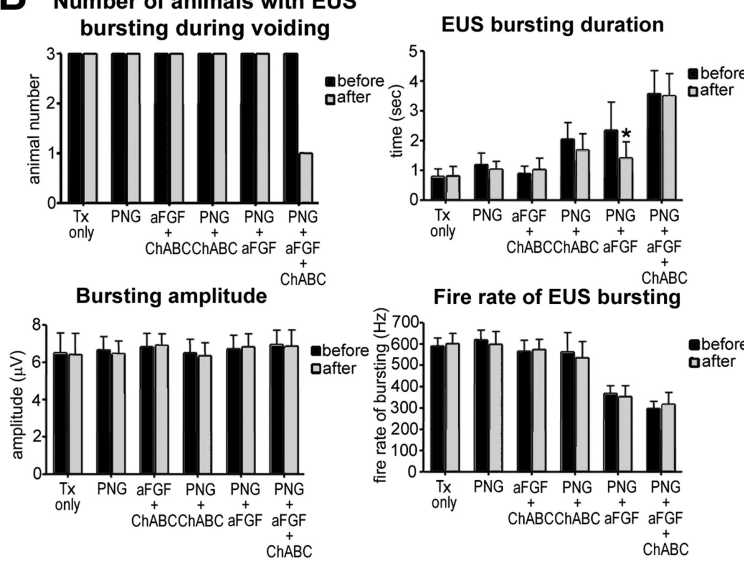

Fire rate of EUS bursting
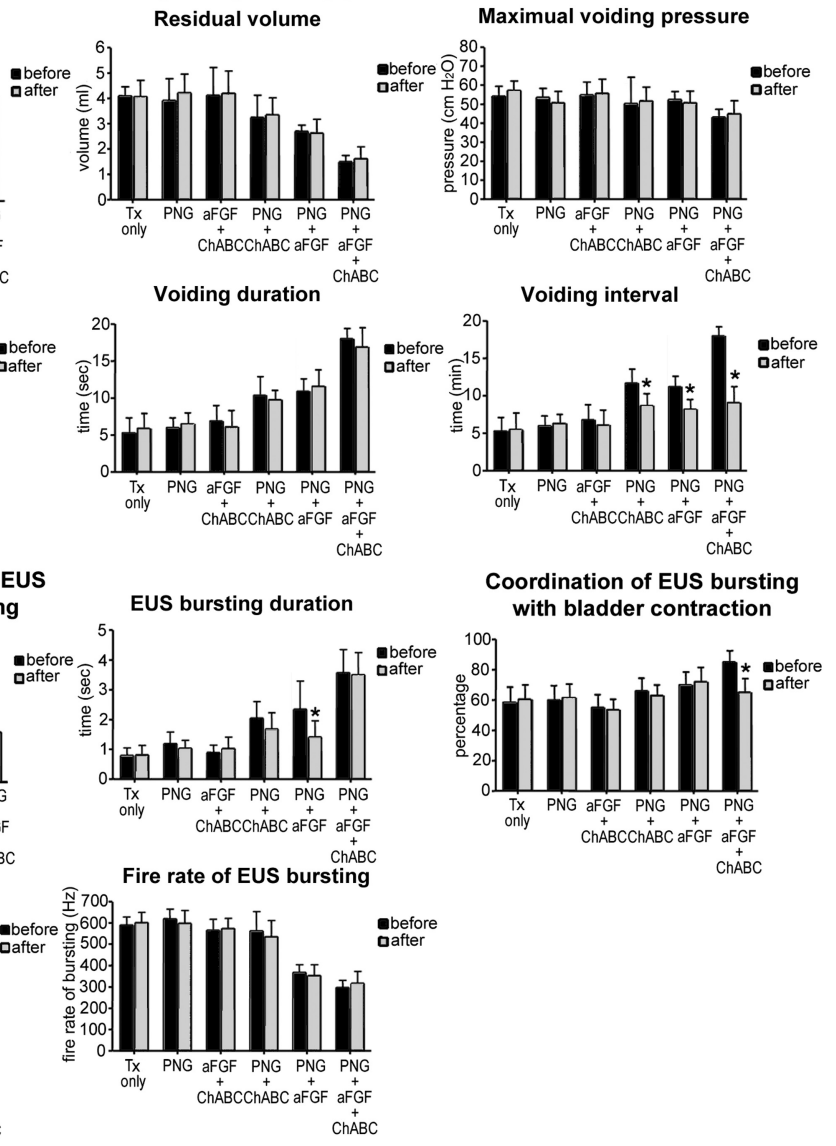

Figure 13. CMG and EUS EMG analysis after methysergide application. $\boldsymbol{A}$, There is no significant difference in CMG parameters after methysergide application in the Tx-only, PNG, and aFGF + ChABC groups. The PNG + ChABC and PNG + aFGF groups showed significantly decreased voiding intervals after methysergide application. The PNG + aFGF + ChABC group showed significantly increased time to first void and decreased voiding intervals. $\boldsymbol{B}$, Methysergide application did not alter EUS EMG parameters in Tx-only, PNG, aFGF + ChABC, and PNG + ChABC groups. EUS bursting length was reduced in PNG + aFGF group after methysergide application. The PNG + aFGF + ChABC group showed elimination of EUS bursting activity and no coordination between bladder contractions with EUS bursting after methysergide application. ${ }^{*} p<0.05$ when compared with the before treatment.

FGF as a trophic factor is unusual in this respect because other neurotrophins, such as NGF, BDNF, or neurotrophin-3, promote a more branched pattern of axonal growth that tends to be constraining to elongation ( $\mathrm{Lu}$ and Tuszynski, 2008; Lu et al., 2012a). Thus, FGF seems to allow axons to grow more readily through the territory in which it is expressed. FGF may also alter the maturation state (Höke and Silver, 1996; Fawcett and Asher, 1999) or change the morphology of astrocytes at the graft/cord interface into a more primitive bipolar shape (Imura et al., 2006; Goldshmit et al., 2012) that improves the ability of axons to pass through. ChABC may also aid in aligning astrocytes because the enzyme has been shown to enhance integration of Schwann cells and astrocytes by altering the production of inhibitory matrices that form between them when they are compelled to interact with one another after transplantation (Grimpe et al., 2005).

It is now well established that the application of $\mathrm{ChABC}$ alone or in combination with other interventions, including PNGs or cellular transplantation, can promote sprouting as well as nerve regeneration and functional recovery after SCI (Bradbury et al., 2002; Caggiano et al., 2005; Fouad et al., 2005; Houle et al., 2006; Massey et al., 2006; Karimi-Abdolrezaee et al., 2010; Alilain et al., 2011; Bukhari et al., 2011; Imagama et al., 2011; Jefferson et al.,
2011; Wang et al., 2011). Typically, however, the extent of axonal regrowth/ sprouting within the CNS compartment is fairly restricted to the region of CSPG degradation (Barritt et al., 2006; Starkey et al., 2012). We have identified a subset of neurons situated primarily within the brainstem and reticular formation (and which are known to play important roles in bladder function) (McMahon and Spillane, 1982) as well as the propriospinal system that can regrow lengthy axons once a permissive environment that allows them past the glial scar is provided. We saw no evidence of regeneration by cortico-spinal or rubro-spinal axons (unlike the results by Cheng et al., 1996), which is one possible reason for the limited recovery of locomotor function (BassoBeattie-Bresnahan score improved from 2 to $\sim 7$ in the triple-combination animals; data not shown). Although propriospinal (Bareyre et al., 2004; Fenrich and Rose, 2011; van den Brand et al., 2012), 5-HT (Azmitia et al., 1978; Molliver et al., 1990; Hawthorne et al., 2011), and certain other brainstem neurons (Hill et al., 2001) are well known to possess an enhanced capacity to regenerate or sprout axons relatively short distances after injury, the lengthy regeneration of these as well as those from several other nuclei so far down the cord was quite surprising. Propriospinal neurons have the capacity to regenerate an axon right though very small, carefully crafted lesions in the ventral white commissure (Fenrich and Rose, 2011). Serotonergic neurons express higher levels of GAP-43 and $\beta 1$ integrins than do cortical neurons, which helps them maintain an active growth cone and sprout robustly rather than becoming dystrophic and dying back within the lesion environment (Hawthorne et al., 2011). Indeed, these neuronal populations appear to behave as if they were intrinsically conditioned (Ertürk et al., 2012). Recently, an exciting series of papers has revealed that robust axonal regeneration can be elicited via manipulation of the mTOR/PTEN and SOCS3/STAT3 pathways (Park et al., 2010; Sun et al., 2011; de Lima et al., 2012). It still needs to be determined whether the long-distance regenerating neurons intrinsically modulate these growth regulatory genes. An understanding of the special strengths of these neurons may aid in devising strategies to instill their unique navigational attributes into other types of neurons that fare less well after injury or when they are presented with a regeneration-promoting environment.

The current study provides an experimental framework for stimulating functional regeneration after acute severe SCI. Micturition control is complex and recovery takes a long time, but, rather remarkably, it would appear that certain primitive brainstem-mediated functions lost to SCI such as respiration (Alilain et al., 2011) and urination do possess the capacity to rewire themselves even when a relatively small number of axons can be induced to regenerate beyond the glial scar. However, and importantly, we do not yet know precisely how many and where 
beyond the lesion the functionally relevant synapses need to be re-formed. The critical synapses may occur within the interneuronal pool just beyond the graft in which most fibers end. The future challenge will be to provide even more favorable environments (Deng et al., 2011, 2013) and increase the intrinsic growth potential of these particular supraspinal neurons to facilitate more substantial and rapid axonal regeneration to further enhance recovery of these but also other systems not only after acute but also after chronic SCI.

\section{Notes}

Supplemental material for this article is available at http://filer.case.edu/jxs10/Regeneration_Movies/. Movie 1, Limited axon regeneration in a PNG only animal. A movie made from confocal reconstructions showing that the BDA-labeled fibers grew into the PNG but did not exit. Movie 2, Long-distance axon regeneration in a triplecombination animal. A movie made from confocal reconstructions clearly showing nerve regeneration (BDA-labeled fibers) beyond the PNG/caudal cord interface in a PNG + aFGF + $\mathrm{ChABC}$ animal. This material has not been peer reviewed.

\section{References}

Aguayo AJ, David S, Bray GM (1981) Influences of the glial environment on the elongation of axons after injury: transplantation studies in adult rodents. J Exp Biol 95:231-240. Medline

Alilain WJ, Horn KP, Hu H, Dick TE, Silver J (2011) Functional regeneration of respiratory pathways after spinal cord injury. Nature 475:196-200. CrossRef Medline

Azmitia EC, Buchan AM, Williams JH (1978) Structural and functional restoration by collateral sprouting of hippocampal 5-HT axons. Nature 274:374-376. CrossRef Medline

Bareyre FM, Kerschensteiner M, Raineteau $O$, Mettenleiter TC, Weinmann O, Schwab ME (2004) The injured spinal cord spontaneously forms a new intraspinal circuit in adult rats. Nat Neurosci 7:269-277. CrossRef Medline

Barritt AW, Davies M, Marchand F, Hartley R, Grist J, Yip P, McMahon SB, Bradbury EJ (2006) Chondroitinase $\mathrm{ABC}$ promotes sprouting of intact and injured spinal systems after spinal cord injury. J Neurosci 26:1085610867. CrossRef Medline

Bradbury EJ, Moon LD, Popat RJ, King VR, Bennett GS, Patel PN, Fawcett JW, McMahon SB (2002) Chondroitinase ABC promotes functional recovery after spinal cord injury. Nature 416:636-640. CrossRef Medline

Bukhari N, Torres L, Robinson JK, Tsirka SE (2011) Axonal regrowth after spinal cord injury via chondroitinase and the tissue plasminogen activator (tPA)/plasmin system. J Neurosci 31:14931-14943. CrossRef Medline

Busch SA, Silver J (2007) The role of extracellular matrix in CNS regeneration. Curr Opin Neurobiol 17:120-127. CrossRef Medline

Caggiano AO, Zimber MP, Ganguly A, Blight AR, Gruskin EA (2005) Chondroitinase $\mathrm{ABCI}$ improves locomotion and bladder function following contusion injury of the rat spinal cord. J Neurotrauma 22:226-239. CrossRef Medline

Cameron AP (2010) Pharmacologic therapy for the neurogenic bladder. Urol Clin North Am 37:495-506. CrossRef Medline

Chang HY, Cheng CL, Chen JJ, de Groat WC (2007) Serotonergic drugs and spinal cord transections indicate that different spinal circuits are involved in external urethral sphincter activity in rats. Am J Physiol Renal Physiol 292:F1044-F1053. CrossRef Medline

\section{Alpha-methyl-DL-tyrosine application}
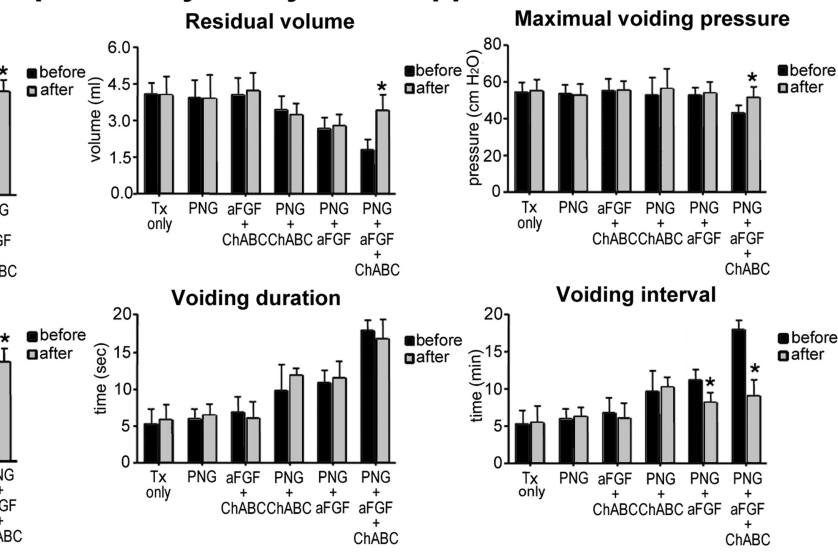

Coordination of EUS bursting with bladder contraction

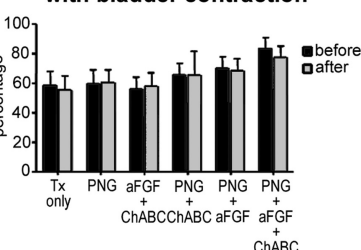

EUS bursting duration
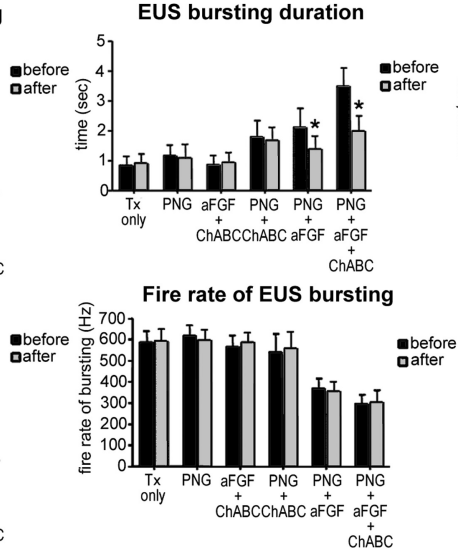

ChABC

$\mathrm{ChABC}$

Figure 14. CMG and EUS EMG analysis after $\alpha$-methyl-DL-tyrosine application. $\boldsymbol{A}$, There was no significant difference in CMG

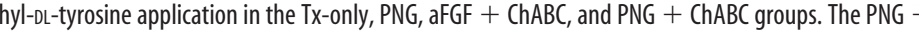
group showed significantly increased time to first void, increased maximal voiding pressure, increased residual volume, decreased , E 列 EUS bursting length after $\alpha$-methyl-DL-tyrosine application. ${ }^{*} p<0.05$ when compared with the before treatment.

Cheng CL, de Groat WC (2004) The role of capsaicin-sensitive afferent fibers in the lower urinary tract dysfunction induced by chronic spinal cord injury in rats. Exp Neurol 187:445-454. CrossRef Medline

Cheng H, Olson L (1995) A new surgical technique that allows proximodistal regeneration of 5-HT fibers after complete transection of the rat spinal cord. Exp Neurol 136:149-161. CrossRef Medline

Cheng H, Cao Y, Olson L (1996) Spinal cord repair in adult paraplegic rats: partial restoration of hind limb function. Science 273:510-513. CrossRef Medline

Cruz CD, Cruz F (2011) Spinal cord injury and bladder dysfunction: new ideas about an old problem. ScientificWorldJournal 11:214-234. CrossRef Medline

Davies SJ, Fitch MT, Memberg SP, Hall AK, Raisman G, Silver J (1997) Regeneration of adult axons in white matter tracts of the central nervous system. Nature 390:680-683. CrossRef Medline

Davies SJ, Goucher DR, Doller C, Silver J (1999) Robust regeneration of adult sensory axons in degenerating white matter of the adult rat spinal cord. J Neurosci 19:5810-5822. Medline

de Groat WC, Araki I, Vizzard MA, Yoshiyama M, Yoshimura N, Sugaya K, Tai C, Roppolo JR (1998) Developmental and injury induced plasticity in the micturition reflex pathway. Behav Brain Res 92:127-140. CrossRef Medline

de Lima S, Koriyama Y, Kurimoto T, Oliveira JT, Yin Y, Li Y, Gilbert HY, Fagiolini M, Martinez AM, Benowitz L (2012) Full-length axon regeneration in the adult mouse optic nerve and partial recovery of simple 
visual behaviors. Proc Natl Acad Sci U S A 109:9149-9154. CrossRef Medline

Deng LX, Hu J, Liu N, Wang X, Smith GM, Wen X, Xu XM (2011) GDNF modifies reactive astrogliosis allowing robust axonal regeneration through Schwann cell-seeded guidance channels after spinal cord injury. Exp Neurol 229:238-250. CrossRef Medline

Deng LX, Deng P, Ruan Y, Xu ZC, Liu NK, Wen X, Smith GM, Xu XM (2013) A novel growth-promoting pathway formed by GDNF-overexpression Schwann cells promotes propriospinal axonal regeneration, synapse formation, and partial recovery of function after spinal cord injury J Neurosci 33:5655-5667. CrossRef

Dolber PC, Gu B, Zhang X, Fraser MO, Thor KB, Reiter JP (2007) Activation of the external urethral sphincter central pattern generator by a 5-HT1A receptor agonist in rats with chronic spinal cord injury. Am J Physiol Regul Integr Comp Physiol 292:R1699-R1706. CrossRef Medline

Ertürk A, Mauch CP, Hellal F, Förstner F, Keck T, Becker K, Jährling N, Steffens H, Richter M, Hübener M, Kramer E, Kirchhoff F, Dodt HU, Bradke F (2012) Three-dimensional imaging of the unsectioned adult spinal cord to assess axon regeneration and glial responses after injury. Nat Med 18:166-171. CrossRef Medline

Fawcett JW, Asher RA (1999) The glial scar and central nervous system repair. Brain Res Bull 49:377-391. CrossRef Medline

Fenrich KK, Rose PK (2011) Axons with highly branched terminal regions successfully regenerate across spinal midline transections in the adult cat. J Comp Neurol 519:3240-3258. CrossRef Medline

Fouad K, Schnell L, Bunge MB, Schwab ME, Liebscher T, Pearse DD (2005) Combining Schwann cell bridges and olfactory-ensheathing glia grafts with chondroitinase promotes locomotor recovery after complete transection of the spinal cord. J Neurosci 25:1169-1178. CrossRef Medline

Fowler CJ, Griffiths D, de Groat WC (2008) The neural control of micturition. Nat Rev Neurosci 9:453-466. CrossRef Medline

Fraser MO (2011) New insights into the pathophysiology of detrusorsphincter dyssynergia. Curr Bladder Dysfunct Rep 6:93-99. CrossRef

Frazier EP, Schneider T, Michel MC (2006) Effects of gender, age and hypertension on beta-adrenergic receptor function in rat urinary bladder. Naunyn Schmiedebergs Arch Pharmacol 373:300-309. CrossRef Medline

Gensel JC, Nakamura S, Guan Z, van Rooijen N, Ankeny DP, Popovich PG (2009) Macrophages promote axon regeneration with concurrent neurotoxicity. J Neurosci 29:3956-3968. CrossRef Medline

Goldshmit Y, Sztal TE, Jusuf PR, Hall TE, Nguyen-Chi M, Currie PD (2012) Fgf-dependent glial cell bridges facilitate spinal cord regeneration in zebrafish. J Neurosci 32:7477-7492. CrossRef Medline

Grimpe B, Pressman Y, Lupa MD, Horn KP, Bunge MB, Silver J (2005) The role of proteoglycans in Schwann cell/astrocyte interactions and in regeneration failure at PNS/CNS interfaces. Mol Cell Neurosci 1:18-29. CrossRef Medline

Hawthorne AL, Hu H, Kundu B, Steinmetz MP, Wylie CJ, Deneris ES, Silver J (2011) The unusual response of serotonergic neurons after CNS Injury: lack of axonal dieback and enhanced sprouting within the inhibitory environment of the glial scar. J Neurosci 31:5605-5616. CrossRef Medline

Hill CE, Beattie MS, Bresnahan JC (2001) Degeneration and sprouting of identified descending supraspinal axons after contusive spinal cord injury in the rat. Exp Neurol 171:153-169. CrossRef Medline

Höke A, Silver J (1996) Proteoglycans and other repulsive molecules in glial boundaries during development and regeneration of the nervous system. Prog Brain Res 108:149-163. CrossRef Medline

Houle JD, Tom VJ, Mayes D, Wagoner G, Phillips N, Silver J (2006) Combining an autologous peripheral nervous system "bridge" and matrix modification by chondroitinase allows robust, functional regeneration beyond a hemisection lesion of the adult rat spinal cord. J Neurosci 26: 7405-7415. CrossRef Medline

Imagama S, Sakamoto K, Tauchi R, Shinjo R, Ohgomori T, Ito Z, Zhang H, Nishida Y, Asami N, Takeshita S, Sugiura N, Watanabe H, Yamashita T, Ishiguro N, Matsuyama Y, Kadomatsu K (2011) Keratan sulfate restricts neural plasticity after spinal cord injury. J Neurosci 31:17091-17102. CrossRef Medline

Imura T, Nakano I, Kornblum HI, Sofroniew MV (2006) Phenotypic and functional heterogeneity of GFAP-expressing cells in vitro: differential expression of LeX/CD15 by GFAP-expressing multipotent neural stem cells and non-neurogenic astrocytes. Glia 53:277-293. CrossRef Medline

Jefferson SC, Tester NJ, Howland DR (2011) Chondroitinase ABC promotes recovery of adaptive limb movements and enhances axonal growth caudal to a spinal hemisection. J Neurosci 31:5710-5720. CrossRef Medline

Jiang HH, Gustilo-Ashby AM, Salcedo LB, Pan HQ, Sypert DF, Butler RS, Damaser MS (2009) Electrophysiological function during voiding after simulated childbirth injuries. Exp Neurol 215:342-348. CrossRef Medline

Jin Y, Ziemba KS, Smith GM (2008) Axon growth across a lesion site along a preformed guidance pathway in the brain. Exp Neurol 210:521-530. CrossRef Medline

Karimi-Abdolrezaee S, Eftekharpour E, Wang J, Schut D, Fehlings MG (2010) Synergistic effects of transplanted adult neural stem/progenitor cells, chondroitinase, and growth factors promote functional repair and plasticity of the chronically injured spinal cord. J Neurosci 30:1657-1676. CrossRef Medline

Kontani H, Hayashi K (1997) Urinary bladder response to hypogastric nerve stimulation after bilateral resection of the pelvic nerve or spinal cord injury in rats. Int J Urol 4:394-400. CrossRef Medline

Kruse MN, Belton AL, de Groat WC (1993) Changes in bladder and external urethral sphincter function after spinal cord injury in the rat. Am J Physiol 264:R1157-1163. Medline

Lee YS, Baratta J, Yu J, Lin VW, Robertson RT (2002a) AFGF promotes axonal growth in rat spinal cord organotypic slice co-cultures. J Neurotrauma 19:357-367. CrossRef Medline

Lee YS, Hsiao I, Lin VW (2002b) Peripheral nerve grafts and aFGF restore partial hindlimb functions in adult paraplegic rats. J Neurotrauma 19: 1203-1216. CrossRef Medline

Lee YS, Lin CY, Robertson RT, Yu J, Deng X, Hsiao I, Lin VW (2006) Regrowth of catecholaminergic fibers and protection of cholinergic spinal cord neurons in spinal repaired rats. Eur J Neurosci 23:693-702. CrossRef Medline

Leung PY, Johnson CS, Wrathall JR (2007) Comparison of the effects of complete and incomplete spinal cord injury on lower urinary tract function as evaluated in unanesthetized rats. Exp Neurol 208:80-91. CrossRef Medline

Lu P, Tuszynski MH (2008) Growth factors and combinatorial therapies for CNS regeneration. Exp Neurol 209:313-320. CrossRef Medline

Lu P, Blesch A, Graham L, Wang Y, Samara R, Banos K, Haringer V, Havton L, Weishaupt N, Bennett D, Fouad K, Tuszynski MH (2012a) Motor axonal regeneration after partial and complete spinal cord transection. J Neurosci 32:8208-8218. CrossRef Medline

Lu P, Wang Y, Graham L, McHale K, Gao M, Wu D, Brock J, Blesch A, Rosenzweig ES, Havton LA, Zheng B, Conner JM, Marsala M, Tuszynski MH (2012b) Long-distance growth and connectivity of neural stem cells after severe spinal cord injury. Cell 150:1264-1273. CrossRef Medline

Massey JM, Hubscher CH, Wagoner MR, Decker JA, Amps J, Silver J, Onifer SM (2006) Chondroitinase $\mathrm{ABC}$ digestion of the perineuronal net promotes functional collateral sprouting in the cuneate nucleus after cervical spinal cord injury. J Neurosci 26:4406-4414. CrossRef Medline

McMahon SB, Spillane K (1982) Brain stem influences on the parasympathetic supply to the urinary bladder of the cat. Brain Res 234:237-249. CrossRef Medline

Molliver ME, Berger UV, Mamounas LA, Molliver DC, O'Hearn E, Wilson MA (1990) Neurotoxicity of MDMA and related compounds: anatomic studies. Ann N Y Acad Sci 600:649-661; discussion 661-664. Medline

Morita T, Iizuka H, Iwata T, Kondo S (2000) Function and distribution of beta3-adrenoceptors in rat, rabbit and human urinary bladder and external urethral sphincter. J Smooth Muscle Res 36:21-32. CrossRef Medline

Neubauer D, Graham JB, Muir D (2007) Chondroitinase treatment increases the effective length of acellular nerve grafts. Exp Neurol 207:163170. CrossRef Medline

Park KK, Liu K, Hu Y, Kanter JL, He Z (2010) PTEN/mTOR and axon regeneration. Exp Neurol 223:45-50. CrossRef Medline

Rabchevsky AG, Fugaccia I, Turner AF, Blades DA, Mattson MP, Scheff SW (2000) Basic fibroblast growth factor (bFGF) enhances functional recovery following severe spinal cord injury to the rat. Exp Neurol 164:280291. CrossRef Medline

Ramon y Cajal S (1928) Degeneration and regeneration of the nervous system. New York: Oxford UP.

Russell JC, Szuflita N, Khatri R, Laterra J, Hossain MA (2006) Transgenic expression of human FGF-1 protects against hypoxic-ischemic injury in perinatal brain by intervening at caspase-XIAP signaling cascades. Neurobiol Dis 22:677-690. CrossRef Medline

Shen Y, Tenney AP, Busch SA, Horn KP, Cuascut FX, Liu K, He Z, Silver J, 
Flanagan JG (2009) PTPsigma is a receptor for chondroitin sulfate proteoglycan, an Inhibitor of neural regeneration. Science 326:592-596. CrossRef Medline

Silver J, Miller JH (2004) Regeneration beyond the glial scar. Nat Rev Neurosci 5:146-156. CrossRef Medline

Starkey ML, Bartus K, Barritt AW, Bradbury EJ (2012) Chondroitinase ABC promotes compensatory sprouting of the intact corticospinal tract and recovery of forelimb function following unilateral pyramidotomy in adult mice. Eur J Neurosci 36:3665-3678. CrossRef Medline

Sun F, Park KK, Belin S, Wang D, Lu T, Chen G, Zhang K, Yeung C, Feng G, Yankner BA, He Z (2011) Sustained axon regeneration induced by codeletion of PTEN and SOCS3. Nature 480:372-375. CrossRef Medline

Teng YD, Mocchetti I, Wrathall JR (1998) Basic and acidic fibroblast growth factors protect spinal motor neurons in vivo after experimental spinal cord injury. Eur J Neurosci 10:798-802. CrossRef Medline

Tsai EC, Krassioukov AV, Tator CH (2005) Corticospinal regeneration into lumbar grey matter correlates with locomotor recovery after complete spinal cord transection and repair with peripheral nerve grafts, fibroblast growth factor 1, fibrin glue, and spinal fusion. J Neuropathol Exp Neurol 64:230-244. Medline van den Brand R, Heutschi J, Barraud Q, DiGiovanna J, Bartholdi K, Huerlimann M, Friedli L, Vollenweider I, Moraud EM, Duis S, Dominici N, Micera S, Musienko P, Courtine G (2012) Restoring voluntary control of locomotion after paralyzing spinal cord injury. Science 336:1182-1185. CrossRef Medline

Wang D, Ichiyama RM, Zhao R, Andrews MR, Fawcett JW (2011) Chondroitinase combined with rehabilitation promotes recovery of forelimb function in rats with chronic spinal cord injury. J Neurosci 31: 9332-9344. CrossRef Medline

Woods M, Carson N, Norton NW, Sheldon JH, Argentieri TM (2001) Efficacy of the beta3-adrenergic receptor agonist CL-316243 on experimental bladder hyperreflexia and detrusor instability in the rat. J Urol 166:11421147. CrossRef Medline

Yang LJ, Lorenzini I, Vajn K, Mountney A, Schramm LP, Schnaar RL (2006) Sialidase enhances spinal axon outgrowth in vivo. Proc Natl Acad Sci U S A 103:11057-11062. CrossRef Medline

Ziemba KS, Chaudhry N, Jin Y, Rabchevsky AG, Smith GM (2008) Targeting axon growth from neuronal transplantation in the adult central nervous system along preformed guidance pathways. J Neurosci 28:340 -348. CrossRef Medline 